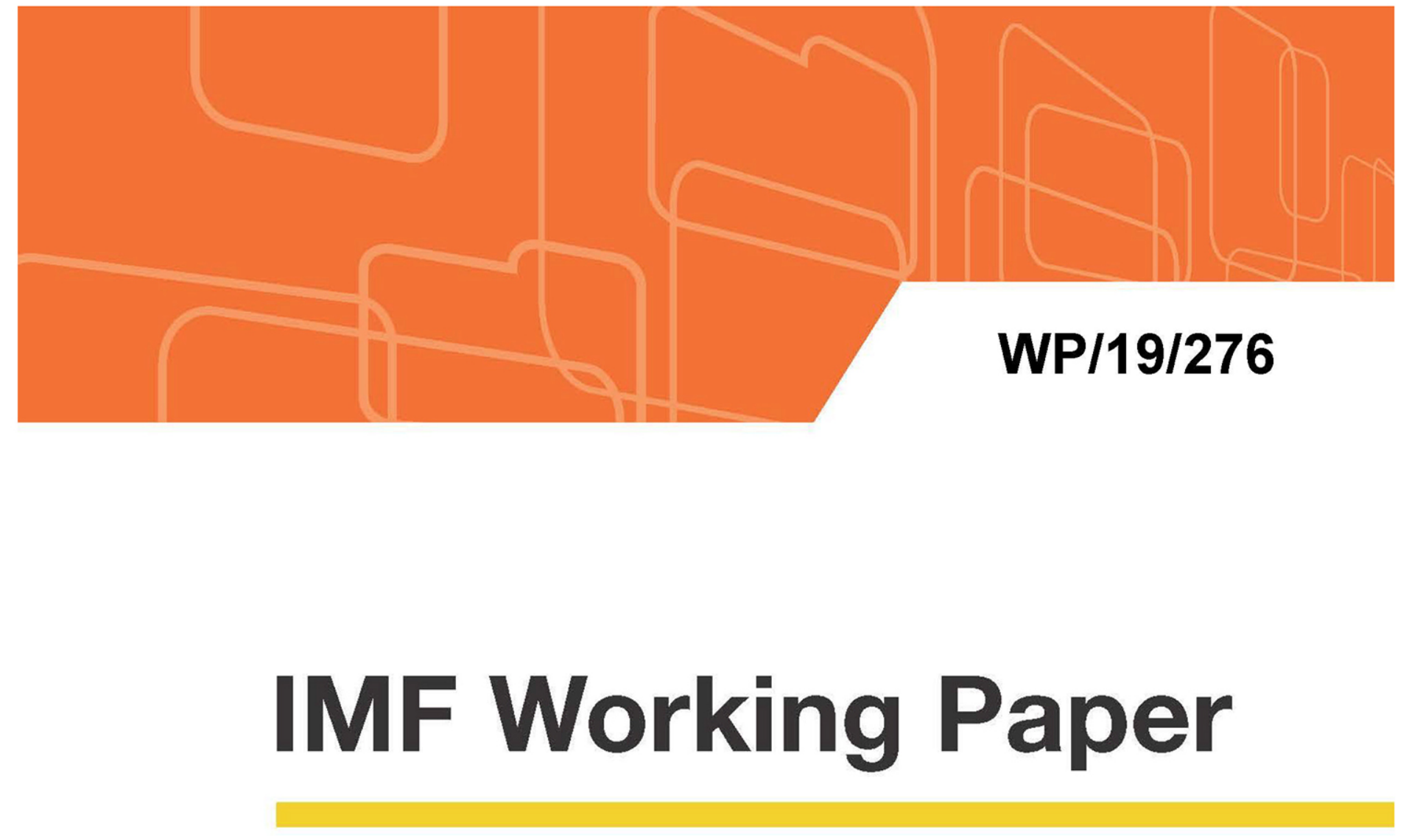

\title{
What is the Impact of Increased Business Competition?
}

by Sónia Félix and Chiara Maggi

IMF Working Papers describe research in progress by the author(s) and are published to elicit comments and to encourage debate. The views expressed in IMF Working Papers are those of the author(s) and do not necessarily represent the views of the IMF, its Executive Board, or IMF management. 


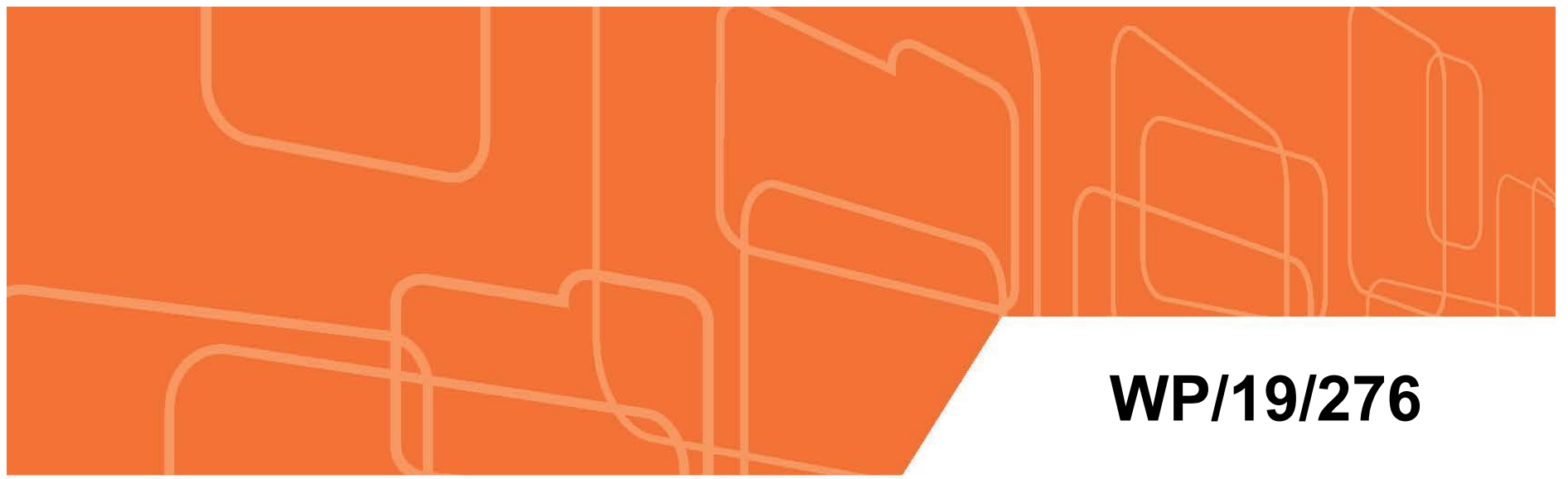

IMF Working Paper

\section{What is the Impact of Increased Business Competition?}

by Sónia Félix and Chiara Maggi

IMF Working Papers describe research in progress by the author(s) and are published to elicit comments and to encourage debate. The views expressed in IMF Working Papers are those of the author(s) and do not necessarily represent the views of the IMF, its Executive Board, or IMF management.

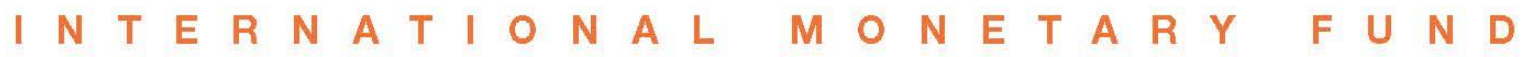




\title{
IMF Working Paper
}

Research Department

\section{What is the Impact of Increased Business Competition?}

Sónia Félix and Chiara Maggi

Authorized for distribution by Romain Alexandre Duval

December 2019

\section{IMF Working Papers describe research in progress by the author(s) and are published to elicit comments and to encourage debate. The views expressed in IMF Working Papers are those of the author(s) and do not necessarily represent the views of the IMF, its Executive Board, or IMF management.}

\begin{abstract}
This paper studies the macroeconomic effect and underlying firm-level transmission channels of a reduction in business entry costs. We provide novel evidence on the response of firms' entry, exit, and employment decisions. To do so, we use as a natural experiment a reform in Portugal that reduced entry time and costs. Using the staggered implementation of the policy across the Portuguese municipalities, we find that the reform increased local entry and employment by, respectively, $25 \%$ and $4.8 \%$ per year in its first four years of implementation. Moreover, around $60 \%$ of the increase in employment came from incumbent firms expanding their size, with most of the rise occurring among the most productive firms. Standard models of firm dynamics, which assume a constant elasticity of substitution, are inconsistent with the expansionary and heterogeneous response across incumbent firms. We show that in a model with heterogeneous firms and variable markups the most productive firms face a lower demand elasticity and expand their employment in response to increased entry.
\end{abstract}

JEL Classification Numbers: E23, E24, E65, L53.

Keywords: markups, business entry, competition, structural reforms.

Authors’ E-Mail Addresses: scfelix@bportugal.pt, cmaggi@imf.org. 


\section{Introduction}

Business competition is a fundamental driver of productivity and output growth. Recently however, extensive research has documented a decline in firm entry across advanced economies (Decker et al., 2014; Hathaway and Litan, 2014), and a rise in industry-level concentration (Grullon et al., 2018; Bajgar et al., 2019). While the causes of the two phenomena are unsettled, there is an increased interest in understanding the macroeconomic implications of policies aimed at increasing entry and competition.

While entrants disproportionally contribute to job creation and output growth (Haltiwanger et al. 2013; Gutiérrez and Philippon 2017; Alon et al. 2018; Pugsley and Sahin 2018), increased entry and business competition may entail some costs. The downsizing or exit of less efficient firms may lead to significant job destruction, which can exacerbate or induce a recession. Accordingly, a common view in the literature is that entry reforms trade off short-term pain for long-term gain (Cacciatore et al., 2016b).

However, there is limited empirical evidence regarding the effects of higher business competition. This is due to important identification challenges. Competition reforms are often implemented in response to poor economic performance. In addition, firm entry, hiring, and investment decisions are endogenous in nature and depend on the state of the economy (Lee and Mukoyama 2008; Bilbiie et al. 2012). So it is hard to distinguish between the dynamics triggered by the policy and other macroeconomic forces affecting the economy. For this reason, the literature has mostly relied on model-based predictions.

This paper makes both an empirical and a theoretical contribution to this question. To empirically study the effects of an increase in entry and business competition, we use as a natural experiment a reform that was implemented in Portugal starting in 2005. The reform reduced the bureaucratic and monetary costs required to start a business, drastically decreasing entry costs for firms. To identify the causal response to the reform, we exploit its staggered implementation over time across municipalities, which provides a quasi-random change in the competitive environment for both entrants and incumbent firms. This allows us to identify both the local macroeconomic impact of the reform, and the underlying firmlevel channels. Specifically, we ask three questions: (i) Did the reform lead to an increase in firm entry? (ii) What was the impact of the reform on local employment? (iii) What are the firm-level mechanisms underlying the observed response of employment? Finally, we present a model of heterogeneous firms and monopolistic competition that delivers consistent predictions with the data and provides novel insights on the channels linking business competition and macroeconomic dynamics.

The Portuguese reform was called Empresa na Hora, which means "Business On the Spot". Before the reform, Portugal was ranked around the 113 th out of 155 countries in the "Doing Business Index" of the World Bank. It would take between 54 to 78 days to complete

CInternational Monetary Fund. Not for Redistribution 
the required bureaucracy to start a new business (Leitão Marques, 2007). After the reform, registering a new business took less than an hour and could be accomplished at one specific office, called One-Stop Shop. ${ }^{1}$ Because of the reform, Portugal climbed to around the 33rd position in the ranking of the World Bank (see Branstetter et al., 2014).

A key feature of the reform is that it was implemented gradually across the country. That is, One-Stop Shops opened over different years in the various municipalities. This was due to constraints on the availability of office space and trained public servants. The staggered implementation of the reform allows us to adopt a generalized difference-in-differences strategy to identify its effects. In particular, we compare the evolution of firm entry, exit, and employment across municipalities with and without the One-Stop Shop in the years preceding and following the opening of the office.

One concern in such empirical setting is that municipalities with the One-Stop Shop were chosen based on past or expected economic performance. If that is the case, it would not be possible to identify the effect of the reform. Our identification assumption, instead, is that the Portuguese municipalities did not follow different trends before the reform (i.e., parallel-trend assumption). We assess the plausibility of this assumption by studying the dynamics of entry, exit, and employment in the years preceding the approval of the reform. Our results show no evidence of divergent trends in the pre-reform period.

Our empirical analysis is based on an administrative firm-level data from Portugal on the population of limited-liability employer firms, i.e., firms with at least one employee. ${ }^{2}$ In addition, we use publicly-available information on the opening dates of the One-Stop Shops in the different municipalities. Our dataset covers the years 2000-2008, that is, we cover up to four years since the implementation of the reform.

In the first part of our empirical analysis, we study the impact of the reform on firm entry and employment at the municipality level. We show that the reform significantly increased entry and that the effect does not fade away within the first four years of implementation of the reform. In municipalities with the One-Stop Shop, entry increased on average by $25 \%$ per year. ${ }^{3}$ Moreover, we find no systematic difference in the evolution of entry over time across reformed and non-reformed municipalities before the opening of the One-Stop Shop. We then study employment and find that, due to the reform, local employment increased on average by $4.8 \%$ per year. That is, we do not find evidence of a short-term pain.

In the last part of the empirical analysis, we explore the micro-level mechanisms underlying the observed increase in employment. To begin, we study the contribution of entrants

\footnotetext{
${ }^{1}$ Total monetary costs to register a new business fell as well, from 2,000 to 360 euro.

${ }^{2}$ This dataset contains detailed information on the year of incorporation, sector of activity up to 5 digits, location at the municipality level, annual turnover, and employment.

${ }^{3}$ The entry rate of limited-liability firms in the Portuguese municipalities averages around $8.5 \%$, so the reform increased annual entry rate by approximately 2 percentage points.
} 
and incumbents to the rise in local employment. We measure that about $60 \%$ of the increase in employment is coming from incumbent firms, which expanded their average size (i.e. intensive margin contribution). The remaining share is due to a rise in the number of entrants (i.e. extensive margin contribution). In fact, the average size of new entrants is unchanged or lower than before.

In the last part of the empirical analysis, we delve deeper in the response of incumbent firms and find that the most productive ones are driving the employment expansion in treated municipalities. In particular, we find that only the firms belonging to the top tercile of the productivity distribution increased their workforce in treated municipalities. ${ }^{4}$

In the second part of the paper, we present a theoretical framework to compare our empirical findings with the predictions of models featuring heterogeneous firms and monopolistic competition. We first present a general setting with heterogeneous firms and monopolistic competition in general equilibrium. Our framework is static and nests a variety of demand systems used in the literature on firm dynamics. We find that standard models, which assume a constant elasticity of substitution (CES), are inconsistent with the observed response of incumbents to the reform. ${ }^{5}$ Under CES, an increase in the mass of operating firms drives down employment across all firms. Moreover, the fall in employment is of the same magnitude for all firms, regardless of their productivity. Instead, we show that a model which includes heterogeneous and variable demand elasticities is consistent with our empirical findings. ${ }^{6}$ A key feature of the model is that the most productive firms, which have a higher market share, face a lower demand elasticity. Additionally, the demand elasticities increase with the number of available firms. In this environment, the most productive incumbents expand their employment following a rise in firm entry.

The model allows us to interpret the economic channels of the reform. There are two main forces arising from a decline in entry costs: a competition effect and an aggregate demand effect. The former leads to a decline in the price level. Then, the fall in prices increases the real wage and so employment. The rise in employment increases total spending, which we refer to as the aggregate demand effect. These mechanisms are present both with CES and translog demand. Accordingly, a key takeaway on the macroeconomic impact of a rise in business competition (i.e., taking general equilibrium forces into account), is that higher

\footnotetext{
${ }^{4}$ Importantly, since current level of productivity is endogenous to a firm's employment decision, we follow different criteria to rank firms based on their level of revenue productivity in 2004 - the year preceding the announcement and implementation of the reform.

${ }^{5}$ Our result is consistent with a growing literature in trade and international macro, which provides empirical support to moving beyond CES demand, and provides theoretical models with more general demand systems (see for instance Atkeson and Burstein 2008; Zhelobodko et al. 2012; Edmond et al. 2015; Arkolakis et al. 2018).

${ }^{6}$ Our model features the symmetric translog demand model proposed by Feenstra (2003).
} 
competition can lead to an expansion in aggregate employment whenever it significantly reduces the aggregate price level. This happens when the increase in competition happens simultaneously across sectors.

The CES and translog models differ in the microeconomic channels through which the competition effect leads to a reduction in prices. In both cases, the competition effect is harmful for incumbents, everything else constant. When demand is CES, incumbent firms are hurt because, ceteris paribus, the increase in entry leads to an increase in the number of varieties and so to a reduction in the market share of each firm. Additionally, while markups remain constant, the aggregate consumption good becomes cheaper as the number of varieties increases. This is a standard implication of the "love-of-variety" effect. Moreover, all incumbents are hurt in a homogeneous way, regardless of their productivity, since they all face the same constant demand elasticity. With translog demand, instead, in addition to the "love-of-variety" effect, the decline in the price level is coming from a reduction in markups across all firms and a shift in the distribution of operating firms towards those with higher productivity, which charge lower prices. Moreover, incumbent firms are hurt in a heterogeneous way. In particular, the more productive incumbents are hurt by less, because they face lower demand elasticities. Since for the most productive firms the effect of the expansion in aggregate demand is stronger than the negative effect of higher competition, they end up expanding their workforce, while accounting for a lower market share.

In the last part of the paper, we calibrate the translog demand model to the Portuguese data and numerically explore the mechanisms driving the firm-level and aggregate response to the reform. We find that the underlying productivity distribution matters for the response of aggregate employment. The rise in local employment is maximized when the initial productivity distribution is more dispersed. This is because the reallocation of production towards the most productive firms is stronger. Finally, we use the numerical example to assess the economy-wide impact of the reform. Because the economy-wide labor supply elasticity is lower than the one at the municipality level, the country-wide employment effect of the reform is weaker. For a unitary labor supply elasticity, the average annual increase in aggregate employment reduces from $4.84 \%$ to $1.67 \%$.

Related Literature. This paper is related to papers in macroeconomics on structural reforms and firm dynamics. Finally, the empirical part connects to an applied microeconomics literature on entrepreneurship.

The seminal paper on the macroeconomics of structural reforms is Blanchard and Giavazzi (2003), which presents a theoretical framework to study the impact and channels of a reduction in entry costs. Building on those insights, a more recent literature has characterized the effects of a reduction in entry costs in the context of quantitative general equilibrium macro 
models, given the identification challenges faced by empirical work on this topic. ${ }^{7}$

Specifically, a strand of research has investigated structural reforms in a New Keynesian economy with a representative firm and binding Zero Lower Bound constraint on monetary policy (Eggertsson 2012; Eggertsson et al. 2014). ${ }^{8} \mathrm{~A}$ second strand of literature is based on models with endogenous producer entry, a representative firm and translog demand function, building on the framework of Bilbiie et al. (2012). Cacciatore and Fiori (2016) extend the latter by including capital adjustment costs and search frictions in the labor market. ${ }^{9}$ In all cases firms are homogeneous and the reform leads to a short-run recession.

Our evidence on the heterogeneity of the responses of incumbent firms is in line with Aghion et al. 2005, 2009; Gutiérrez and Philippon 2017. ${ }^{10}$

By including firm heterogeneity, we connect to a vast literature on firm dynamics. This literature builds on the work by Hopenhayn (1992) and Melitz (2003), and focuses on the role of entrants and incumbents in shaping aggregate dynamics (see for instance Lee and Mukoyama 2008; Clementi and Palazzo 2016). Relative to these papers, we show empirically and theoretically that firm heterogeneity and CES demand are not sufficient to deliver responses in line with our empirical evidence.

Another strand of literature investigated the impact of the decline in firm formation in the aftermath of the financial crisis (see for instance Sedlácek 2014; Gourio et al. 2016). ${ }^{11}$

Finally, our empirical analysis connects to a broad literature in applied microeconomics in the field of barriers to entry and entrepreneurship (see for instance Betrand and Kramarz 2002; Viviano 2008; Hombert et al. 2014). Papers by Kaplan et al. (2011) and Branstetter

\footnotetext{
${ }^{7}$ Empirical contributions on this topic are based on macroeconometric models that mostly exploit crosscountry variation in the aggregate index of product-market deregulation provided by the OECD. Other works use national/sectorial reform shocks identified via narrative analysis, (see for instance Bouis et al. 2016; Duval and Furceri 2018). These analyses find that benefits from the product market reform materialize slowly and have no relevant short-run effects.

${ }^{8}$ In this framework, structural reforms are recessionary, because they lead to lower prices and higher real interest rates. This rise induces households to postpone consumption (via the so-called substitution effect), which leads to a contraction in aggregate output. We share with these models a setting with exogenous and fixed interest rate. However, our analysis highlights expansionary forces associated with the reform that are not supportive of the "substitution effect".

${ }^{9}$ Related papers, which add New Keynesian and/or open macro features, are Cacciatore et al. 2016a,b,c and Cacciatore et al. (2017). Cacciatore and Fiori (2016) is further extended by Colciago (2018), who embeds oligopolistic competition.

${ }^{10}$ The authors, however, focused on innovation or capital investment, while our focus is on labor demand. Moreover, their explanation for heterogeneity relied on monopolistic market structure and strategic behavior, while our market specification is more general and firms are atomistic.

${ }^{11} \mathrm{~A}$ key takeaway from these works is that the role of entrants is minimal in the short-run, while it increases over time as new firms grow. We complement this work by providing causal evidence on the fact that entry matters also in the short run, mostly because of its impact on incumbents.
} 
et al. (2014) are the closest to our empirical work, as they exploit the staggered implementation of an entry deregulation reform to study its impact on firm creation. Branstetter et al. (2014), in particular, studied the same Portuguese reform as we do. While we share the idea of exploiting the staggered opening of One-Stop Shops across the Portuguese municipalities, we depart from this work both in terms of research questions and empirical methodology. Their research aims at characterizing entrants and testing models of occupational choice, while our focus is on characterizing the response of firms and macro aggregates to the reform.

Outline. The remainder of the paper is organized as follows. Section 2 describes the reform and the data. Section 3 presents the empirical analysis. Section 4 presents the theoretical and numerical analysis. Section 5 concludes.

\section{Institutional Setting and Data}

In this section we present the institutional details of Empresa na Hora (Section 2.1), and provide an overview of the macroeconomic background leading to the reform (Section 2.2). We then describe our dataset and provide some statistics on the Portuguese business sector.

\subsection{Portugal and the Empresa na Hora Reform}

After joining the European Monetary Union in 1999, Portugal entered a prolonged slump, with anemic productivity and output growth (Blanchard, 2007). When a country with relevant structural weaknesses like Portugal loses control of its monetary policy and exchange rate, the call for structural reforms becomes even more compelling.

Until 2005, Portugal was considered one the least business-friendly countries, according to international ranking. In particular, before the reform, it took 56-78 days to start a business, making it slower than the Democratic Republic of Congo, as documented by Leitão Marques (2007). An entrepreneur needed to fill in around 20 forms, provided by different public agencies, and complete 11 procedures, for a total cost of $€ 2,000$.

From February 2005 to May 2005 a cross-departmental task force, called Unidade de Coordenação da Modernazição Administrativa (UCMA), designed and managed a broad plan of modernization and simplification of public services for both citizens and businesses. The plan was called SIMPLEX and covered areas such as digitalization of income tax declaration, simplification of immigration admission procedures, and approval of licenses and permits for different industrial and retail activities.

The reform that we are studying, which was called Empresa na Hora, was a relevant part of this broader plan and was aimed at significantly reducing both time and monetary 
costs of starting a business. The program made it possible to start a business "on the spot", by means of a single personal visit to an official Registry. UCMA designed standardized pre-approved documents created on pre-defined firm names. ${ }^{12}$ Within an hour, on average, an entrepreneur receives an official legal person identification card, a Social Security number and a registration of the enterprise in the Business Registry. Monetary costs shrunk to $€ 360$, making this procedure among the cheapest in Europe. The law was approved on July $6^{\text {th }}$, 2005 (Decreto Lei 111/2005).

The program involved virtually all sectors of economic activity and was intensively advertisted by the government, making its macroeconomic implications relevant. International institutions strongly supported the initiative. Accordingly, Branstetter et al. (2014) report that the European Commission selected Portugal for the European Enterprise Award in 2006. The country also moved from averaging around the 113th position (out of 155 countries) in the Doing Business Index of the World Bank to around the 33rd.

There are several features of the program that require a deeper discussion, since they will be key in our empirical analysis. First, the program was implemented in a staggered fashion across the different municipalities. This was mostly due to budget constraints and the need to assess the program and train public servants. As soon as the Decreto Lei was approved in July 2005, six One-Stop Shops were opened in four different cities: Coimbra, Aveiro, Moita and Barreiro. Over the following years the program gradually expanded across the country. Table 5 is taken from Branstetter et al. (2014) and describes the timing of the opening of the One-Stop Shops across Portugal. Out of the 308 municipalities, 99 had a One-Stop Shop by the end of 2008. Figure 5 shows the pattern of the opening of One-Stop Shops in a map of the country.

A second feature of the program is that a firm was allowed to register in any OneStop Shop, regardless of the location of the company. In our empirical exercise, however, we assume that firms registered in the same municipality in which they were operating. Conversations with public officials reassured us that the relevant coverage of each One-Stop Shops was local, so that the number of new firms registered in a One-Stop Shop in a given municipality and year provides a good approximation of the number of new firms in the same municipality and year. Nevertheless, as we will argue in details in our discussion on the identification strategy (see Section 3.1), this aspect would, if anything, bias our estimates on the expansionary effect of the reform downwards.

\footnotetext{
${ }^{12}$ Note, however, that it is possible for an entrepreneur to request a personalized name for the business and have all documents ready withing two business days.
} 


\subsubsection{Implementation of Empresa na Hora}

Our identification strategy exploits the staggered opening of the One-Stop Shops across the Portuguese municipalities. The gradual implementation of the reform was motivated by constraints in the availability of both trained public officials to run the program and physical venues to open the offices. This is why One-Stop-Shops generally took advantage of pre-existing Trade Registry Offices and Business Formality Centers (Branstetter et al., 2014). Accordingly, conversations with public officials reveal that municipalities were not chosen based on past or expected economic activity, which would invalidate our empirical analysis. We now provide some first statistical evidence supporting this claim.

In Table 6 we present the summary statistics of the Portuguese municipalities organized in four partitions. In columns (1) and (2) we summarize the information on Treated relative to Never-Treated municipalities. We consider as Treated those municipalities in which a OneStop Shop opened by the end of 2008. Columns (3) and (4) refer to the Early-Treated and Late-Treated municipalities. We define the former as all those municipalities in which a OneStop Shop opened in 2005-2006. The Table characterizes the different municipality groups according to measures of firm demographics, aggregate macroeconomic characteristics and the sector composition of economic activity. It provides the mean and standard deviation of each variable, as well as the $25^{\text {th }}$ and $75^{\text {th }}$ percentiles. We notice that the different municipality groups did not significantly differ from each other in the pre-reform period. In fact, the standard deviations are very high. This is because there is a strong heterogeneity across the municipalities within each cohort. Accordingly, while municipalities in different groups had similar $25^{\text {th }}$ and $75^{\text {th }}$ percentiles, the gaps between the two are wide.

While this descriptive evidence provides a first pass on the absence of relevant economic criteria in choosing the order the implementation of the reform across the country, it is not sufficient to support our identification strategy. In fact, the latter requires that economic variables evolved homogeneously over time across the different cohorts of municipalities. We address this issue in detail in Section 3.1.

\subsection{Data and Summary Statistics}

Our analysis mainly relies on one dataset with detailed administrative records on the universe of limited-liability firms with at least one employee in Portugal. We cover the years 20002008. The dataset is called Quadros de Pessoal and is built from a census submitted each year in October. The dataset is managed by the Portuguese Ministry of Employment and Social Security and provides information at the firm, establishment, and worker level. In this project we use annual information on firms' entry, exit, sector of activity (provided at the 5-digit level), location at the municipality level, annual nominal sales, and employment. 
This choice is justified by the fact that Empresa na Hora concerned the creation of new firms rather than the opening of establishments. Moreover, while it is true that the opening of an establishment may change local competition and affect our estimates, over $93 \%$ of firms in Portugal have only one establishment.

While the reform was approved in 2005, the time coverage of our dataset allows us to include the five years preceding the reform and inspect the presence of pre-reform trends that may harm the validity of our analysis. Our sample ends in 2008, as there was a drop in the coverage of the Quadros in the following years. As a consequence, we can measure the impact of the reform during the first four years of implementation. However, since the reform was implemented gradually, we are not able to track all reformed municipalities for the same number of years after the opening of the local One-Stop Shop.

We exploit the panel structure of the dataset to construct a measure of firm exit. In particular, we say that a firm exists if it stops appearing in our dataset for at least two consecutive years. ${ }^{13}$ As mergers and acquisitions play a very marginal role in Portugal, we are confident about our measure. In addition, because our dataset originally has information on private employer firms of any legal form (such as cooperatives, or sole proprietorships), we dropped all pre-existing firms that change their legal form to limited liability company over their life cycle. This allows to avoid capturing the effect of the reform on changing the legal form of existing businesses.

Our final dataset has, on average, 125,000 non-financial private corporations per year, spanning all private sectors of the economy, except for Mining, Electricity, Gas and Water, and Insurance. Table 7 in the Appendix provides the relevant summary statistics for the non-financial employer firms in our dataset. In the time window considered, the average entry rate is $7.5 \%$ and exit rate is $9.5 \%$. Information on the size distribution across firms reveals that the Portuguese business sector is mostly characterized by very small enterprises: $50 \%$ of firms have less than 4 employees and $50 \%$ of entrants have less than 2 .

We complement the Quadros de Pessoal with other publicly available datasets. The first is provided by the Instituto dos Registos e Notariado, equivalent to the Portuguese Business Registry, and contains the exact opening date of each One-Stop Shop across the Portuguese municipalities. The second is provided by the Instituto Nacional de Estatística and includes municipality-level data on total residents and more detailed local demographic information.

\footnotetext{
${ }^{13}$ This method is equivalent to define exit as the last time a firm appeared in the dataset for more than $97 \%$ of the cases.
} 


\section{Empirical Analysis}

In this section, we describe the methodology and the results of the empirical analysis. We start by describing the identification strategy and its underlying assumptions (Section 3.1). We then show the results on the impact of the reform on firm creation (Section 3.2) and local employment (Section 3.3). Next, we move to the analysis of the underlying channels. In particular, we study the contribution of younger firms and older incumbents to the observed aggregate response of employment (Section 3.4.1, 3.4.2 and 3.4.3). We then explore the role of incumbents heterogeneity (Section 3.4.4). Lastly, we present more disaggregated evidence at the level of the sector of economic activity (Section 3.5).

\subsection{Empirical Specification and Identification}

To study the impact of the reform, we exploit Empresa na Hora as a natural experiment. We use a generalized difference-in-differences specification that uses the staggered opening of the One-Stop Shops across the Portuguese municipalities. In most of our specifications, our unit of analysis is a municipality in a given year. More specifically, our baseline specification is the following:

$$
y_{m, t}=\alpha_{m}+\delta_{t}+\sum_{\tau} \beta_{\tau} \mathbb{1}\left(t-\tau=\tau_{0, m}\right)+\gamma X_{m, t}+\epsilon_{m, t}
$$

In this regression, $\alpha_{m}$ and $\delta_{t}$ are the municipality and year fixed effects, respectively, $X_{m, t}$ is a vector of controls, which we will discuss in more detail in Section 3.2, $\epsilon_{m, t}$ is an error term with the usual statistical properties. Importantly, $\mathbb{1}\left(t-\tau=\tau_{0, m}\right)$ is a municipality-year dummy that equals 1 whenever municipality $m$ is $\tau$ years from the opening of its office. A negative value for $\tau$ corresponds to the years preceding the reform. Because of the staggered implementation of the reform, the year of the opening of the local One-Stop Shop varies by municipality, i.e., $\tau_{0, m}$ varies with $m$. We normalize $\beta_{-1}=0$, so that $\beta_{\tau}$ measures the average treatment effect at the municipality level for each time lag and lead relative to the year prior to the opening of the office. In particular, $\beta_{\tau}$ captures the following variation:

$$
\beta_{\tau}=\underbrace{E\left[y_{(\tau)}^{\text {treated }}-y_{(-1)}^{\text {treated }}\right]}_{\text {treated municipalities }}-\underbrace{E\left[y_{(\tau)}^{\text {control }}-y_{(-1)}^{\text {control }}\right]}_{\text {control municipalities }} .
$$

The key identification assumption is that the variation in the dependent variable, at the municipality level, and for each year after the opening of the One-Stop Shop, is only due to the reform. This is the "parallel-trend assumption". In other words, we require that all the unobserved determinants of the outcome, as reflected in the residual, evolve in parallel over time for the different municipalities. Identification assumptions are inherently not testable, 
as they refer to unobserved scenarios. However, since our dataset includes the 5-year period before the approval of the reform, our regression model can explicitly test for the presence of differential trends among the observables of the Treated and Control municipalities. Ideally, we expect statistically insignificant coefficients for the years preceding the reform and statistically significant coefficients afterwards. As we show in the next sections, there is no trend in the periods leading to the reform. This reassures us that municipalities do not have differential trends over the observables across the treated and control groups.

\subsection{Analysis of Entry}

We now show how the reform affected firm creation. To do so, we construct our dependent variable, $y_{m, t}$ by aggregating the number of entrants in each municipality and year and scaling it over 1,000 residents. This provides a more homogeneous measure of entry across the different municipalities. Following the description of our identification strategy, our main regression equation is

$$
y_{m, t}=\alpha_{m}+\delta_{t}+\sum_{\tau=-7}^{\tau=3} \beta_{\tau} \mathbb{1}\left(t-\tau=\tau_{0, m}\right)+\gamma_{m} \mathbb{1}\left(\text { Municipality }_{m}=1\right) t+\epsilon_{m, t} .
$$

In this regression, $\alpha_{m}$ and $\delta_{t}$ are municipality and year fixed effects, respectively. The indicator $\mathbb{1}\left(t-\tau=\tau_{0, m}\right)$ refers to the time lag or lead of the reform for each municipality, and we normalize for $\beta_{-1}$ to be equal to zero. In our benchmark regression, we allow for municipality-specific trends. That is, we let our vector of controls in equation (1) - $X_{m, t}$ - be defined as $X_{m, t} \equiv \mathbb{1}$ (Municipality $\left.{ }_{m}=1\right) t$. Since the municipalities within the treatment and control groups are highly heterogeneous, allowing for municipality-specific trends provides cleaner estimates of the impact of the reform over time. We cluster standard errors at the municipality level.

Figure 6 presents our estimates for $\beta_{\tau}$ for different lags and leads. Since the timing of the increase in entry coincides with the opening of the One-Stop Shops in the different municipalities, we are reassured that our results capture the impact of the reform. We see that the opening of the One-Stop Shops significantly increased annual firm entry at the municipality level. The coefficients in Figure 6 refer to the absolute change in the annual number of entrants per 1,000 residents at the municipality level. Using back-of-the-envelope calculations, we find that this increase corresponds to an annual rise in local entry between $12 \%$ to $40 \%$, corresponding to an average of $25 \%$ per year following the reform. Since the pre-reform value of our entry rate in the Treated municipalities is around 8.5\%, the reform led to an approximate increase in the entry of two percentage points. Note, however, that the coefficients for the $t+2$ and $t+3$ lags are noisier, because they are based on a smaller 
number of treated municipalities. For this reason, we prefer stressing the average increase, and the positive sign and significance of our coefficients over the entire time span.

As described in Section 2.1, a firm could register in a different municipality than where it was operating. As a consequence, entrepreneurs living in a municipality belonging to the control group could have driven to the closest One-Stop Shop. However, we assume that firms registered in the same municipality in which they were operating. While we mentioned that One-Stop Shops operated predominantly on a local scale, the possibility of driving from a Control municipality to the closest One-Stop Shop would bias our estimates downwards. To the extent that we see a positive and statistically significant effect of the reform, we do not view this feature of the reform as a concern.

Our entry results are robust to a number of different specifications. In particular, we relax municipality-specific trends and allow trends to differ across groups of municipalities defined over some pre-reform characteristics. In one such specifications, we rank municipalities based on pre-period values of population and predominance of a service-oriented economy, and allow for decile-specific trends. This is shown in Figure 14 in the Appendix. As can be seen in the Figure, the coefficients of $\beta_{\tau}$ do not differ substantially. ${ }^{14}$

\subsection{Analysis of Local Employment}

We now move to the analysis of employment. We use equation (2) and define the dependent variable $y_{m, t}$ as the log of municipality-level employment in a given year normalized over 1,000 residents. We choose to aggregate the firm-level information at the municipality level to remedy the measurement error associated with firms of very small size.

Differently from the entry regression, we choose $t-3$ as a reference (rather than $t-1$ ) - i.e., $\beta_{-3}=0$. This choice simply allows for a more transparent display of the employment response to the reform. Since the reform became perfectly anticipated by the incumbents once it started to be implemented in 2005, the response of aggregate employment captures not only the direct impact of higher entry and incumbents' reaction to actual entry, but also incumbents' reaction to expected entry. This means that each $\beta_{\tau}$ in the employment regression captures the impact of both an actual and an expected change in entry. To the extent that firms face convex adjustment costs in labor, we should expect incumbents to start adjusting their workforce even before the actual opening of the One-Stop Shop in their municipality.

Figure 7 shows the resulting regression coefficients for each reform lag and lead. We see that employment increased significantly in Treated municipalities relative to the Control

\footnotetext{
${ }^{14}$ In results not shown, we also include quadratic and cubic time trends, and allow for separate trends for the municipalities belonging to the different deciles of total population only. Our results are noisier but robust to this specification.
} 
ones. While the coefficients are statistically significant only for the year of the reform and onwards, it is worth highlighting that employment started rising two years prior the reform. Since the lags from $t-7$ to $t-3$ are flat and not statistically different from zero, the slight increase in employment in $t-2$ and $t-1$ likely captures the adjustment of employment by incumbents anticipating a change in their competitive environment and not differential pre-trends across municipalities.

We interpret the coefficients as the cumulative percentage increase in municipality-level employment relative to $t-3$. Accordingly, we see that employment increased by $5 \%$ in the year of the reform, and then continued growing at an average annual rate of $4.8 \%$. Results on employment dynamics are robust to different trend specifications, which are reported in the Appendix. ${ }^{15}$

While the reform setting allows to estimate the causal impact of the reduction in entry costs on employment, we stress that our estimates of a $4.8 \%$ increase measure a local effect. In particular, we claim that this represents an upper bound on the impact of the reform on country-level employment. The response of local employment is higher than the aggregate one for two main reasons. First, our estimates refer to the private sector only, and so include within-municipality employment movements to and from government-owned entities. Second, the local effect is an upper bound for the national effect because it includes crossmunicipality movement of workers. ${ }^{16}$

\subsection{Analysis of the Underlying Channels}

In this section, we explore the micro-level forces underlying our results on local employment. We start by decomposing the increase in employment between the contributions of entrants and young firms to the contribution of older incumbents (Section 3.4.1). We then study the extent to which the responses of these two groups are driven by an intensive or extensive margin of adjustment. Accordingly, we investigate the evolution of the average size of the firms in each group (Section 3.4.2), and the changes in the exit probability in each group (Section 3.4.3). We then study whether the employment and exit decisions of incumbent firms masks some relevant firm heterogeneity (Section 3.4.4).

\footnotetext{
${ }^{15}$ For instance, Figure 14 in the Appendix shows the results of a specification that allows for trends by municipalities grouped by deciles of total residents and per-capita value of activity in services during the pre-reform period.

${ }^{16}$ To check whether our evidence of a local increase in employment is consistent with aggregate labor market variables, we plot in Figure 13 the evolution of the Portuguese labor force participation rate and unemployment. The Figure shows that the unemployment rate flattened out around the time of the reform, after having trended upwards in the preceding years, and that the labor force started rising approximately from 2005. Aggregate dynamics seem then consistent with our estimated local effects.
} 


\subsubsection{The Response of Employment by Age Groups}

We start by analyzing the role of young firms and older incumbents in explaining the observed response of local employment. We classify firms according to three age classes: age $0-5$, $6-15$, and older than 15 (15+ henceforth). That is, we keep the analysis of incumbents of age $6-15$ and $15+$ distinct.

We aggregate the employment of firms in each municipality and year by the three age groups, and estimate equation (2) separately for each age group. ${ }^{17}$ We classify firms based on their current age. This means that the sample of firms is not constant over time. This method identifies the contribution of the different age groups under the identification assumption that firms belonging to any age group in the Treated municipalities would have behaved as the corresponding ones in the Control municipalities absent the reform, and absent different trends across the municipalities.

Figure 8 shows the results of these regressions. With the caveat for firms older than 15 years showing a noisier and essentially flat response - mostly due to the small and uneven distribution of such firms across the different municipalities - we see that both young firms and older incumbents contribute positively to the rise in local employment. Moreover, we do some back of the envelope calculations to understand the relative contribution of each age group to the overall increase in local employment. To do so, we use the coefficients from the age-group regressions and combine them with information on the average employment share of each age group in the pre-reform period. This exercise reveals that around $60 \%$ of the overall increase in local employment is due to the response of incumbents older than 5 years old, while entrants and young firms account for the remaining $40 \%$.

While evidence on the positive contribution of incumbents to local employment growth is new and of interest by itself, the estimates in Figure 8 are silent on the mechanisms underlying these responses. As a next step, we investigate the extent to which the results are driven by an intensive or an extensive margin of adjustment. The former is related to changes in employment accounted by operating firms, the latter captures the role of entry and exit.

17 The reason why we chose to aggregate employment at the municipality level for each age group deserves further discussion. An alternative strategy could have been using firm-level data on employment. In that case, the $\beta_{s}$ on each time lag and lead would measure the impact of the reform on the size of the average firm by age group, given the sample of surviving firms in each period. While firm-level regressions allow us to rely on a much larger sample and on more controls, the resulting coefficients are subject to an upward bias. Since exiting firms are on average smaller than surviving ones, results from firm-level regressions artificially lead to an increase in the size of the average firm. Aggregate employment by the different age groups, instead, solves this selection-into-exit problem. 


\subsubsection{Analysis of the Intensive Margin of Adjustment by Age Groups}

To capture the intensive margin of adjustment, we study the evolution of the average size of firms in the different age groups. We construct this measure using the following ratio

$$
y_{m, a, t}=\frac{\sum_{i \in(m, a, t)} \text { employment }_{i}}{\sum_{i \in(m, a, t)} \text { active firms }_{i}},
$$

that is, we sum the employment of each firm $i$ belonging to municipality $m$, age group $a$ and year $t$, and divide it by the corresponding value for the number of operating firms. We then use this measure as the dependent variable in the regression equation (2).

Figure 9 shows the estimated coefficients. We notice that the average size of incumbents increased, while that of entrants and young firms remained unchanged. This means that entrants and young firms contributed to the aggregate rise in employment exclusively by the fact that the number of entrants increased after the reform, that is, by the extensive margin. Incumbents, instead, contributed via the intensive margin. This result is robust to relaxing municipality-specific trends and allowing for different trends (see Figure 14 in the Appendix).

An important implication of the observed expansion by incumbents is that the entry and employment impact of the reform are not merely driven by firms moving from the informal to formal market; indeed, there was an actual increase in the number of operating firms.

Evidence of the expansion of incumbent firms following increased entry is novel and inconsistent with the predictions of current workhorse models of firm dynamics, as explained in Section 4. What this evidence does not say, however, is whether the increase in the size of incumbents holds along the whole distribution of firms or whether it is driven by a smaller subset of them.

\subsubsection{Analysis of the Extensive Margin of Adjustment by Age Groups}

To get a better understanding of the role of the extensive margin in shaping local aggregate dynamics, we turn to the analysis of exit. In particular, we study whether and how the reform affected the exit probability of firms in the different age groups.

Our analysis of exit is conducted at the firm level. This means that we study the evolution of the exit probability for the average firm. ${ }^{18}$

Our baseline firm-level regression is specified as follows:

$$
\operatorname{Pr}\left(\text { exit }_{i t}=1\right)=\alpha_{m}+\delta_{t}+\sum_{\tau=-7}^{\tau=3} \beta_{\tau} \mathbb{1}\left(t-\tau_{0, m}=\tau\right)+\sum_{m} \gamma_{m} \mathbb{1}\left(\text { Municipality }_{m}=1\right) t+\epsilon_{i, t} .
$$

\footnotetext{
${ }^{18}$ In contrast to the analysis of employment, the analysis of exit at the firm level is not subject to problems of selection or to measurement errors. For these reasons, we prefer exploiting the maximum amount of information available for our estimates.
} 
exit $_{i t}$ is an indicator variable equal to 1 if firm $i$ exits operations in year $t$. By allowing for the municipality-effect only, we are controlling just for within-municipality variation, while we allow for variation across sectors of economic activity. We do this to remain consistent with the previous municipality-level regressions.

We estimate equation (3) keeping one age group at a time. Panel (a) of Figure 10 shows the resulting estimated coefficients. We see that the exit probability for the average firm remained mostly unaffected by the reform across all age groups. ${ }^{19}$

\subsubsection{Analysis of the Heterogeneous Response of Incumbents}

In this section, we explore the possibility of an underlying heterogeneity across incumbent firms. The dimension of heterogeneity we study is differences in productivity across firms. Exploring the role of heterogeneity based on current measures of productivity leads to biased estimates: the current productivity of the firm is endogenous to its employment decisions. As a consequence, we classify firms based on a proxy for their idiosyncratic productivity measured in the period before the implementation of the reform. For this reason, we can only study the heterogeneity of the responses by incumbent firms. Given the available data, we proxy for labor productivity using the ratio of nominal sales over employment for each firm, that is, revenue labor productivity.

To be able to study the heterogeneous impact of the reform on the largest sample of young firms, we choose the year 2004 - being the year preceding the announcement and implementation of the reform - as the initial year of our analysis. We rank operating firms in 2004 according to our proxy of labor productivity. Our specification ranks firms based on their revenue labor productivity within each age group (0-5, 5-15, 15+), 3-digit sector of activity, and municipality. Comparing firms' revenue labor productivity in 2004 within these narrow classes minimizes the heterogeneity in capital intensity and prices across firms. We then aggregate total employment and total exit at the municipality-year level for the first and third terciles, and separately study their evolution over the different reform lags and leads as in the regression equation (2). We use as dependent variable the implied municipality-level aggregate of employment and exit for each tercile normalized by 1,000 residents.

Figure 11 shows the results of this exercise for both total employment and exit (Panels (a) and (b), respectively). The estimates unveil substantial heterogeneity in firms' response, according to their productivity level. We see that the increase in aggregate employment is driven by the most productive firms, while the behavior of the bottom tercile remained

\footnotetext{
${ }^{19}$ This result is robust to replacing the municipality fixed effect with a fixed effect for the municipality interacted with the 3 -digit sector of activity, as shown in Panel (b). It is also robust to replacing municipalityspecific trends with trends by deciles of municipalities based on total residents and per-capital value of activity in services in the pre-reform period, as shown in Figure 14 in the Appendix.
} 
unchanged after the reform. A similar story emerges from the analysis of exit. In particular, the number of exiting firms in the top tercile dropped significantly after the reform, while the exit behavior of the bottom tercile remained unaffected. As a robustness exercise, we alternatively rank firms based on their productivity within 3-digit sector of economic activity and municipality (that is, pooling the age groups together). Our results are weaker but still robust to this specification, as shown in Figure 15 in the Appendix. ${ }^{20}$

\subsection{Analysis of the Reform by Sector}

We conclude the empirical analysis by providing evidence on the impact of the reform disaggregated by sector of economic activity. We consider sectors classified at the 1-digit level. This is because any finer classification leads to very noisy results, given that that the firm coverage across municipalities may get extremely uneven. We focus on manufacturing and services only, which are larger and more homogeneously distributed across the municipalities. We redo the exercises presented in the previous sections, separately for these two macro sectors.

Figure 12 compares entry, exit, employment and the behavior of incumbents for firms operating in the manufacturing and service sectors. We start from the analysis of entry. This Figure reveals that entry grew significantly after the reform for the service sector, while it remained flat for manufacturing. This result is not surprising. Indeed firms in the manufacturing sectors are highly intensive in capital, so they face high fixed capital investment. As a consequence, entry decision may not be substantially influenced by the change in time and monetary entry costs induced by the reform. Another interpretation of this result is to consider services and manufacturing as non-tradable and tradable goods, respectively. The firms in the service sector are more influenced by variations in local demand, and so are more responsive to the change in the local economy induced by the opening of the One-Stop Shop.

We then look at employment and find that it increases for the service sector, while it did not significantly change for manufacturing. Next, we investigate the impact of the reform on the average size of firms in different age groups across the two sectors. We see that the average size of entrants and young firms in the service sector decreased. This is consistent with the fact that the smallest firms should be more responsive to a reduction in entry costs. On the other hand, incumbents expanded their average size in services, and mildly did so also in manufacturing. ${ }^{21}$

\footnotetext{
${ }^{20} \mathrm{We}$ also find that our results are robust to decile-specific trends by municipalities based on residents and per-capita value of activity in services, as shown in Figure 16.

${ }^{21}$ We consider the evidence on the expansion of incumbent firms in manufacturing as suggestive, given the small number of firms in the sample, which translates into noisy coefficients.
} 


\section{Theoretical Analysis}

In this section, we study to what extent the empirical findings of Section 3 are consistent with the predictions of a model with heterogeneous firms and monopolistic competition. We start by describing a general framework that nests a variety of models of monopolistic competition (Section 4.1). We then study two specific models that are nested in the general framework. The first is the standard CES model with a continuum of firms (Section 4.2). The second is a model with a symmetric translog demand specification (Section 4.3). The latter allows the demand elasticity to differ across firms, based on their market share, and to vary with the mass of operating firms. We compare the predictions of the model under CES demand and under the symmetric translog specification. We then study additional properties of translog demand in a numerical example (Section 4.4). We find that unlike the CES demand model, the translog specification delivers predictions in line with the empirical findings: The response of incumbent firms varies with their productivity, and the most productive ones expand in response to the rise in entry.

\subsection{Framework}

We now provide a description of a model of heterogeneous firms and monopolistic competition under a generalized demand system.

\subsubsection{Consumers}

The economy has a representative consumer. The consumer gets his income from supplying labor at wage $w$ and from the profits of the firms. Given the schedule of prices $\left\{p_{i}\right\}_{i \in \mathcal{M}}$, we can express the demand for the differentiated goods in general terms as

$$
q_{i}=\mathcal{D}\left(p_{i}, M, E, \tilde{P}\right)
$$

where $p_{i}$ is the firm's price, $M$ is the mass of operating firms, $E$ is total expenditure in the economy, and $\tilde{P}$ is a general index defined over $p_{i}$ as

$$
\tilde{P}=\tilde{\mathcal{P}}\left(\left\{p_{i}\right\}_{i \in M}\right)
$$

with $\frac{\partial \tilde{\mathcal{P}}}{\partial p_{i}}>0, \forall i . \mathcal{D}$ is a continuously differentiable function that is decreasing in the firmspecific price $p_{i}$, in $M$ and in $\tilde{P}$. Additionally, it is increasing in total expenditures $E$. That is, $\mathcal{D}_{1}, \mathcal{D}_{2}, \mathcal{D}_{4} \leq 0$ and $\mathcal{D}_{3} \geq 0$. We define the aggregate price index as $P$, which is a function of the schedule of prices

$$
P=\mathcal{P}\left(\left\{p_{i}\right\}_{i \in M}\right),
$$


with $\frac{\partial \mathcal{P}}{\partial p_{i}}>0$, for all $i$. Note that we allow $\tilde{P}$ to be different than $P .{ }^{22}$

\subsubsection{Firms}

The economy has a continuum of heterogeneous firms that are indexed by $i \in[0, M]$. $M$ is comprised of an exogenous mass of incumbents, $M_{I}$, and an endogenous mass of entrants, denoted by $M_{E}$. Firms are heterogeneous in their productivity, $a_{i}$. Production is linear in labor, so that $y_{i}=a_{i} l_{i}$, where $l_{i}$ is the amount of labor used for production in firm $i$.

To enter the market, a firm needs to pay $f_{e}$ units of the aggregate final good. After paying the entry cost, a firm draws its idiosyncratic productivity from the distribution $F(a)$. We assume that this distribution is the same as the productivity distribution of incumbent firms. The endogenous measure of entrants, $M_{E}$, is determined in equilibrium by an expected zero-profit condition. That is, in equilibrium the expected profits of an entrant are equal to the entry cost. This condition is given by:

$$
\int V\left(a_{i} ; M, E, \tilde{P}\right) d F\left(a_{i}\right)=f_{e} P
$$

where $V($.$) is the profits function of firm i$ without entry costs. Upon entry, the problem of an entrant is the same as that of any incumbent. In particular, each firm in the market solves:

$$
\begin{aligned}
V\left(a_{i} ; M, E, \tilde{P}\right)=\max _{p_{i}, q_{i}, l_{i}} p_{i} q_{i}-w l_{i} \quad \text { s.t. } \quad q_{i} & =a_{i} l_{i} \\
q_{i} & =\mathcal{D}\left(p_{i}, M, E, \tilde{P}\right) .
\end{aligned}
$$

For ease of notation, we define the marginal cost of firm $i$ as $m c_{i} \equiv \frac{w}{a_{i}}$ and its markup as $\mu_{i} \equiv p_{i} / m c_{i}$. Solving the firm's problem, we get the markup takes the following form in equilibrium :

$$
\mu_{i}=\frac{\varepsilon\left(p_{i}, M, E, \tilde{P}\right)}{\varepsilon\left(p_{i}, M, E, \tilde{P}\right)-1},
$$

where $\varepsilon($.$) is the elasticity of substitution of demand of good i$, defined as $\varepsilon\left(p_{i}, M, E, \tilde{P}\right)=$ $-\frac{\mathcal{D}_{1}}{\mathcal{D}} p_{i}$. Given the firm's price, the labor demand of firm $i$ is given by:

$$
l_{i}=\frac{1}{a_{i}} \mathcal{D}\left(p_{i}, M, E, \tilde{P}\right) .
$$

\footnotetext{
${ }^{22}$ In the CES case, both indices will coincide. In the translog model, instead, they are not equal, as shown in Section 4.3.
} 


\subsubsection{Aggregate Variables}

We take the aggregate labor supply function as given. We assume it depends only on the real wage in the economy. One preference specification that gives rise to such labor supply function is the one introduced by Greenwood, Hercowitz and Huffman (1988). In particular, we define aggregate labor supply $L^{S}$ as follows:

$$
L^{S}=\left(\frac{w}{P}\right)^{\nu}
$$

where $\nu>0$ is the labor supply elasticity.

While entrants make zero profits on average, incumbents make positive profits. We assume that profits of incumbents are distributed lump-sum to households. So that total expenditure by workers is equal to

$$
E^{w}=w L+M_{I} \int V\left(a_{i}\right) d F\left(a_{i}\right),
$$

where the second term represents the aggregate profits of incumbent firms, since their measure is $M_{I}$. Total real expenditure $\frac{E}{P}$, which includes the amount spent by firms for the fixed entry costs, is equal to

$$
\frac{E}{P}=\frac{E^{w}}{P}+f_{e} M_{E}
$$

\subsubsection{Equilibrium}

Without loss of generality, we normalize the wage level to one. An equilibrium in this economy consists of aggregate variables $\left\{M, M_{E}, \tilde{P}, P, L, E\right\}$, the schedule of prices set by firms, $\left\{p_{i}\right\}_{i \in[0, M]}$, the demand schedule for labor, $\left\{l_{i}\right\}_{i \in[0, M]}$, and firm-level goods produced $\left\{q_{i}\right\}_{i \in[0, M]}$, such that:

(i) An expected zero-profit condition (7) holds if the measure of entrants in equilibrium is positive, $M_{E}>0$, and expected profits are weakly lower than zero if $M_{E}=0$.

(ii) Given aggregate variables, the allocations solve the firm's problem. That is, the markup set by each firm satisfies equation (8), labor demand $l_{i}$ satisfies (9), and the level of production $q_{i}$ satisfies (4) for all $i$.

(iii) The labor market clears. In particular, $L^{S}=\int_{0}^{M} l_{i} d i$, with $L^{S}$ determined by (10).

(iv) The goods market clears. That is:

$$
\frac{E}{P}=\int_{0}^{M} \frac{p_{i}}{P} q_{i} d i
$$

where $\frac{E}{P}$ is given by equation (12). 
Having described the theoretical framework in general terms, we now study the impact of the reform under CES and symmetric translog demand specifications. In particular, we analyze the comparative statics of the reform with respect to aggregate labor, and labor at the firm level. We consider the reform as a reduction in entry costs, $f_{e}$. This leads to an increase in the mass of operating firms $M$.

\subsection{The CES Case}

We start by considering the CES case, which is characterized by the following expression for the demand function of each firm $i$ :

$$
q_{i}=\left(\frac{p_{i}}{P}\right)^{-\sigma} \frac{E}{P}
$$

where the aggregate price index is given by

$$
P=\left(\int_{0}^{M} p_{i}^{1-\sigma} d i\right)^{\frac{1}{1-\sigma}}
$$

$\sigma>1$ is the elasticity of substitution of the good produced by firm $i$. Notice that the elasticity is constant and equal across firms. This implies that also the markup charged by each firm is constant, and equal to $\frac{\sigma}{\sigma-1}$ for all $i$.

The presence of constant demand elasticities and markups is key to determine the response of aggregate and firm-level variables to the reform, and the underlying economic forces. We show it by studying the impact of the reform on the labor demand of each firm $l_{i}$ and the aggregate employment level $L$.

We summarize the response of the labor demand of each firm to the reform in the following proposition.

Proposition 1. Under CES, the response of labor demand is homogeneous across firms. Moreover,

$$
\frac{\partial \ln l_{i}}{\partial \ln M}=-\frac{\sigma-1-\nu}{\sigma-1}
$$

Proof. The proof of this Proposition and all the proofs of this section can be found in Appendix A.2.

The Proposition above implies that the employment level of each firm falls if $\sigma-1>\nu$, i.e., if the demand elasticity for each good $i$ is higher than the elasticity of labor supply. Otherwise, the labor demand of each firm increases. This means that the impact of the reform on labor demand is theoretically ambiguous. However, it is worth pointing out that the usual calibration in the literature is $\sigma \in[3,7]$ and $\nu \in[0.5,2]$. Therefore, under standard calibration values, the reform leads to a decline in the size of all operating firms. 
Despite the contraction in the size of each incumbent firm, aggregate labor demand increases. This is stated in the next Proposition.

Proposition 2. Under CES, aggregate labor $L$ increases in response to a rise in the mass of operating firms $M$. That is,

$$
\frac{\partial \ln L}{\partial \ln M}>0
$$

The results in Propositions 1 and 2 can be explained by the joint combination of two forces: a competition effect and an aggregate demand effect. The first is driven by the increase in the number of operating firms $M$ and leads to a reduction in the aggregate price level $P$. In particular, the fall in the price level is due to the "love-of-variety" effect. Since incumbents firms now account for a lower expenditure share, they downsize their workforce. Moreover, since incumbent firms face the same demand elasticity, they will all be subject to the same decline in demand and employment, regardless of their productivity.

The aggregate demand effect is the result of the decline in the aggregate price index, which raises labor supply and aggregate demand. Under standard calibration of $\nu$, the rise in aggregate demand is not strong enough to counteract the contraction in size of incumbent firms induced by the rise in competition. As a result, the increase in total labor $L$ presented in Proposition 2 is entirely driven by the extensive margin, i.e., by the increase in the mass of operating firms $M$. This means that the CES specification is not only inconsistent with heterogeneous response by incumbents, but also stands in contrast with our finding that the majority of the rise in aggregate labor is due to an increase in incumbents' labor demand.

\subsection{An Economy with Variable Markups}

Consider again the same framework, but suppose that the demand is derived from a symmetric translog expenditure function. This specification was proposed by Feenstra (2003) and leads to a homothetic utility function, with no closed-form representation, and with a non-constant price elasticity of the corresponding demand functions.

Under the symmetric translog specification, the demand for good $i$ is defined as

$$
q_{i}=\left[\frac{1}{M}-\gamma\left(\ln p_{i}-\overline{\ln p}\right)\right] \frac{E}{p_{i}},
$$

where the average price level is given by

$$
\overline{\ln p}=\left(\frac{1}{M} \int_{0}^{M} \ln p_{i} d i\right) .
$$


In addition, the aggregate price index is given by

$$
\ln P=\frac{1}{2 \gamma M}+\int_{i=1}^{M} \frac{1}{M} \ln p_{i}+\frac{1}{2} \int_{0}^{M} \int_{0}^{M} \frac{\gamma}{M} \ln p_{i}\left(\ln p_{j}-\ln p_{i}\right) d i d j,{ }^{23}
$$

which can be rewritten as

$$
\ln P=\frac{1}{2 \gamma M}+\mathbb{E}(\ln p(a))-\frac{1}{2} \gamma M \mathbb{V}(\ln p(a)) \cdot{ }^{24},
$$

with $\mathbb{E}(\ln p(a))$ indicating the average of $\ln p\left(a_{i}\right)$, and $\mathbb{V}(\ln p(a))$ its variance. The solution to the firm's problem delivers

$$
p_{i}=\underbrace{\left(1+\frac{s_{i}}{\gamma}\right)}_{\mu_{i}} \underbrace{\frac{1}{a_{i}}}_{m c_{i}}
$$

where $s_{i}$ is the expenditure share of good $i$, given by

$$
s_{i}=\max \left\{0, \frac{1}{M}-\gamma\left[\ln p_{i}-\overline{\ln p}\right]\right\} .
$$

For simplicity, we assume that the lowest productivity level - $\underline{a}-$ is high enough, such that its market share is greater than zero. In other words, we assume all firms are producing a positive amount $s_{i}>0$ for all $i{ }^{25}$ Having introduced $s_{i}$, we express the demand elasticity in the translog framework as implied by (8):

$$
\varepsilon_{i}=1+\frac{\gamma}{s_{i}}
$$

There are two important properties concerning the demand elasticity - and so markups in the translog framework. First, the elasticity of each firm $i$ is increasing in the mass of operating firms $M$. This implies that the markup is decreasing in $M$. We prove this result in the following proposition:

Proposition 3. Under translog, the demand elasticity of each firm $i$ is increasing in the mass of operating firms $M$, that is:

$$
\frac{\partial \ln \left(\varepsilon_{i}\right)}{\partial \ln M}>0, \quad \forall i
$$

\footnotetext{
${ }^{23}$ Note that, differently from the specification in Feenstra (2003), we set $\tilde{M}$ to infinity. That is, there is no limit to the number of varieties that can be produced.

${ }^{24}$ The derivations of this result can be found in Appendix A.2

${ }^{25}$ This assumption shuts down the role of exit in shaping aggregate and firm-level responses, consistently with our empirical evidence. In addition, it guarantees equilibrium uniqueness and allows to prove key theoretical and numerical results.
} 
Second, the elasticity of each firm $i$ is increasing in its price level. In equilibrium, this implies that the elasticity is decreasing with the firm's productivity, $a_{i}$. This means that the demand faced by more productive firms is less elastic, so it responds less to changes in the relative price of the firm. This can be seen from (21), after replacing the expression for $p_{i}$ given by (19) into (20).

The dependence of the elasticity $\varepsilon_{i}$ on $M$ and $a_{i}$ puts the translog case in stark contrast with the CES case and delivers richer predictions on the impact of the reform on the labor demand of each firm and on the response of aggregate employment. Accordingly, we provide a key result on the response of the labor demand of each firm $i$ in the following Proposition:

Proposition 4. In the translog framework, the reform has a heterogeneous impact on labor demand at the firm level $l_{i}$. In particular, the response of labor demand is increasing in the productivity of the firm. That is,

$$
\frac{\partial^{2} \ln l_{i}}{\partial \ln M \partial \ln a_{i}}>0 .
$$

The heterogeneous response of labor demand is consistent with evidence from our empirical analysis. In particular, the proof of Proposition 4 reveals that not only is the response heterogeneous, but it is also the case that the most productive firms in the economy expand and the least productive reduce their employment. This is true regardless of parameters specification.

Finally, we study the impact of the reform on aggregate labor L. We prove that aggregate labor L increases in the following Proposition.

Proposition 5. Under translog, aggregate labor $L$ increases in response to an increase in the mass of operating firms $M$. That is

$$
\frac{\partial \ln L}{\partial \ln M}>0
$$

Symmetrically to the CES case, we can explain the results in Propositions 4 and 5 by the working of the competition effect and the aggregate demand effect. The former leads to a reduction in the price level not only through the love-of-variety effect, but also through the reduction of markups by all firms. Similarly to the CES case, incumbent firms are hurt by the competition effect, ceteris paribus. This happens because each firm now charges a lower price. However, because in the translog specification more productive firms face a lower demand elasticity, their demand goes down by less. That is, the more productive firms are relatively less hurt by the rise in competition.

At the same time, the decline in the price level increases labor supply $L^{S}$ and stimulates aggregate expenditure $E$. The latter homogeneously increases the demand faced by each 
firm. The net result of these two forces is that the most productive firms end up hiring more workers. This means that, in response to an increase in $M$, the most productive firms expand their size, while accounting for a smaller share of the entire economy.

All in all, given our empirical findings, the translog demand case seems a more promising framework to study the response of the economy to a reform in the business sector. First, it yields heterogeneous responses by the different firms. Second, a large portion of the expansion of aggregate labor demand can come from incumbent firms.

\subsection{Translog Demand: A Numerical Example}

In the following section, we present a numerical example to deepen the understanding of the economic forces at work with translog demand. To begin, we present the baseline calibration of the model. Then, we move to the analysis of the parameters disciplining the competition and aggregate demand channels and run a number of counterfactual exercises on the firmlevel and aggregate employment impact of the reform. Since we are working with a static model, the goal of this exercise is to provide additional intuition on the theoretical channels of the reform, and not to achieve realistic quantitative results.

\subsubsection{Calibration}

In our baseline calibration, we choose the parameter values to match relevant features of the Portuguese data. We assume that the idiosyncratic productivity is drawn from a Pareto distribution with scale parameter $x_{m}$ and shape parameter $\alpha$. We set the scale parameter of the firms' productivity distribution to $x_{m}=2$. This allows to keep $s_{i}>0$ for all firms after the reform, and so to focus only on the impact of the reform on operating firms. We choose the shape parameter $\alpha$ to match the pre-reform standard deviation of firm size in Portugal, equal to 0.84 . This results in $\alpha=1.08$.

A key parameter which governs the competition channel in the translog specification is $\gamma$, which determines the dispersion of markups and their responsiveness to changes in market shares. As we cannot separately identify $\gamma$ and $M_{I}$, we normalize $M_{I}$ to 1 , and calibrate $\gamma$ to match the pre-reform dispersion of sales in the Portuguese economy. Note that the model implies that the dispersion of sales is greater than the dispersion of size, for any level of $\gamma$. The higher the $\gamma$, the larger is the difference between the dispersion of size and sales. So matching the dispersion of sales, in addition to size, allows us to identify $\gamma$. The standard deviation of sales dispersion is 1.1, resulting in the value of $\gamma$ equal to 1.97.

Finally, we set the labor supply elasticity $\nu$ to match the average annual rise in employment at the municipality level, equal to $4.84 \%$. To compute the rise in employment due to the reform, we assume that the measure of entrants changes from $9 \%$ to $11.25 \%$. This is 
consistent with our empirical findings that annual entry went up by $25 \%$ on average. The resulting estimate of the labor supply elasticity is $\nu=2.86$. Note that this values is higher than the one usually chosen in the literature, which is equal to 2, as in Clementi and Palazzo 2016. A higher labor supply elasticity is consistent with the fact that we identify a local employment response, and not an aggregate employment response. We elaborate on this point in Section 4.5.

Table 1: Baseline Calibration

\begin{tabular}{|l|c|c|c|}
\hline Description & Parameter & Value & Target \\
\hline Mass of incumbent firms & $M_{I}$ & 1 & \\
Productivity scale parameter & $x_{m}$ & 2 & \\
Productivity shape parameter & $\alpha$ & 1.08 & Size dispersion $=0.84$ \\
Markup parameter & $\gamma$ & 1.97 & Sales dispersion $=1.1$ \\
Labor supply elasticity & $\nu$ & 2.86 & Local employment response $=4.84 \%$ \\
\hline
\end{tabular}

\subsubsection{Baseline analysis}

Figure 1 shows the response of labor demand at the firm-level, as a function of the firm's idiosyncratic productivity. As already proven in the theoretical analysis, we see that the change in labor demand at the firm level is increasing in the productivity of the firm. The least productive firms cut their size following a rise in firm entry, while the opposite is true for highly productive firms. We then compute in Table 2 the resulting change in aggregate employment, and decompose the underlying contribution of entrants and incumbents. Out of the matched $4.84 \%$ annual increase in local employment, we find that the bulk of it (approximately 53\%) is coming from incumbents. This is consistent with the empirical analysis, where incumbents accounted for approximately $60 \%$ of the rise in total employment.

Table 2: Response of Aggregate Employment and Contribution of Entrants and Incumbents

\begin{tabular}{|c|c|c|}
\hline$\Delta$ L - Total & $\Delta$ L - Entrants & $\Delta$ L - Incumbents \\
\hline $4.84 \%$ & $2.31 \%$ & $2.54 \%$ \\
& $(47.5 \%)$ & $(52.5 \%)$ \\
\hline
\end{tabular}

The Table computes the total increase in employment and the underlying contribution of entrants and incumbent firms. The second row includes in parenthesis the share of the overall change in employment accruing to entrants and incumbent firms. 
Figure 1: Impact of an Decrease in $f_{e}$ on Incumbents' Labor Demand

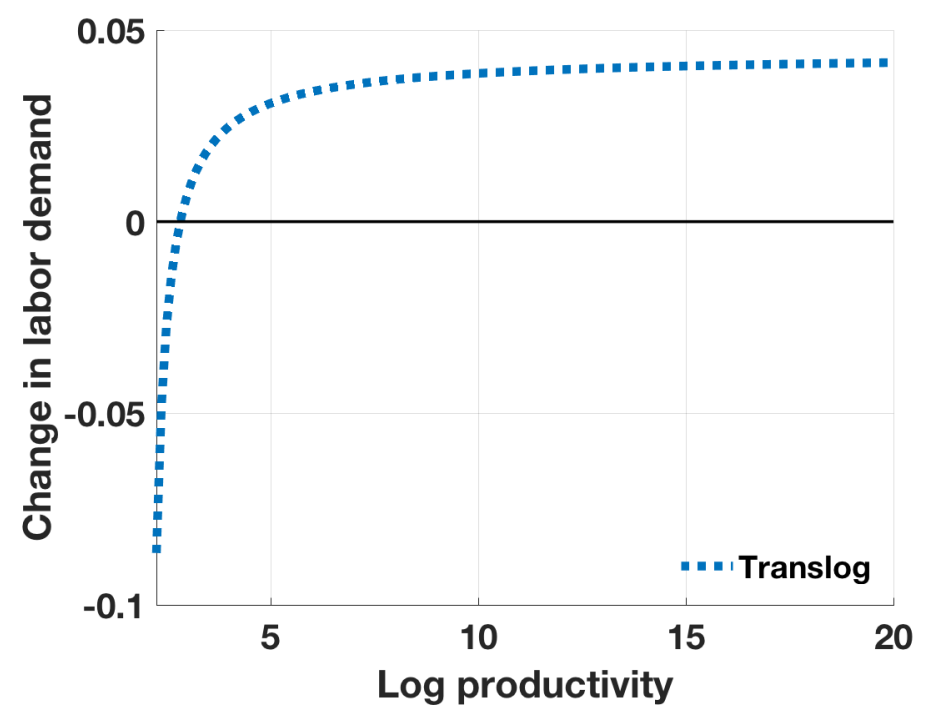

The figure plots the change in the labor demand of each firm as a function of its idiosyncratic productivity, following a decrease in entry costs $f_{e}$. The dotted line instead shows that the response in labor demand depends on firm's productivity. More productive firms decrease their labor demand by less, and even expand it for sufficiently high levels of productivity.

\subsubsection{Inspecting the mechanism}

In this section, we use the numerical example to inspect the underlying channels of the reform. We do so by studying how the strength of the competition effect, being the decline in the price level triggered by the rise in entry, is disciplined by $\gamma$ and $\alpha$. The former governs both markup dispersion and the responsiveness of markups to changes in market shares. The latter governs the dispersion of productivity across firms.

The role of the translog preference parameter, $\gamma$. In Table 3 , we compare the responses of aggregate employment to the reform, for different values of $\gamma$. We see that the effect of the reform on aggregate employment is decreasing in $\gamma$.

To understand why this is the case, consider again the expression of firm markup in the translog model:

$$
\mu_{i}=1+\frac{1}{\gamma} s_{i} .
$$

A higher level of gamma has three implications on firm markups: (i) lower level of markup for each firm, (ii) less dispersed markup distribution, and (iii) less responsive markups to changes in market shares. These two implications shape the effectiveness of the reform, in different directions. Less dispersed markups favor the reallocation of production towards the 
most productive firms, following the rise in firm entry. This is shown in the first panel of Figure 2. As a consequence, lower markup dispersion suggests that the fall in the price level due to the reform (and so the rise in employment) is stronger for higher $\gamma$.

On the other hand, while lower markup dispersion strengthens the impact of the reform, lower responsiveness to the measure of firms weakens it. As a consequence, the fall in prices and rise in employment would be weaker when $\gamma$ is higher. Given the results in Table 3, the latter force dominates, so that the impact of the reform is stronger when $\gamma$ is lower. Moreover, as shown in Table 3, when the overall employment effect of the reform increases, so does the relative contribution of incumbents.

Table 3: Response of Aggregate Employment and Contribution of Entrants and Incumbents for Different $\gamma$

\begin{tabular}{|l|c|c|c|}
\hline & $\gamma=\mathbf{0 . 9 7}$ & $\boldsymbol{\gamma}=\mathbf{1 . 9 7}$ & $\boldsymbol{\gamma}=\mathbf{2 . 9 7}$ \\
\hline $\boldsymbol{\Delta} \boldsymbol{L}$ - Total & $7.32 \%$ & $4.84 \%$ & $4.08 \%$ \\
$\mathbf{\%} \boldsymbol{\Delta} \boldsymbol{L}$ - Entrants & $32.3 \%$ & $47.7 \%$ & $56.1 \%$ \\
$\mathbf{\%} \boldsymbol{\Delta} \boldsymbol{L}$ - Incumbents & $67.8 \%$ & $52.3 \%$ & $43.9 \%$ \\
\hline
\end{tabular}

The Table computes the total increase in employment and the underlying contribution of entrants and incumbents for different values of $\gamma$. The results in the second and third row refer to the share of the overall change in employment accruing to entrants and incumbent firms.

Figure 2: Impact of an Decrease in $f_{e}$ on Firms' Labor Demand for different values of $\gamma$
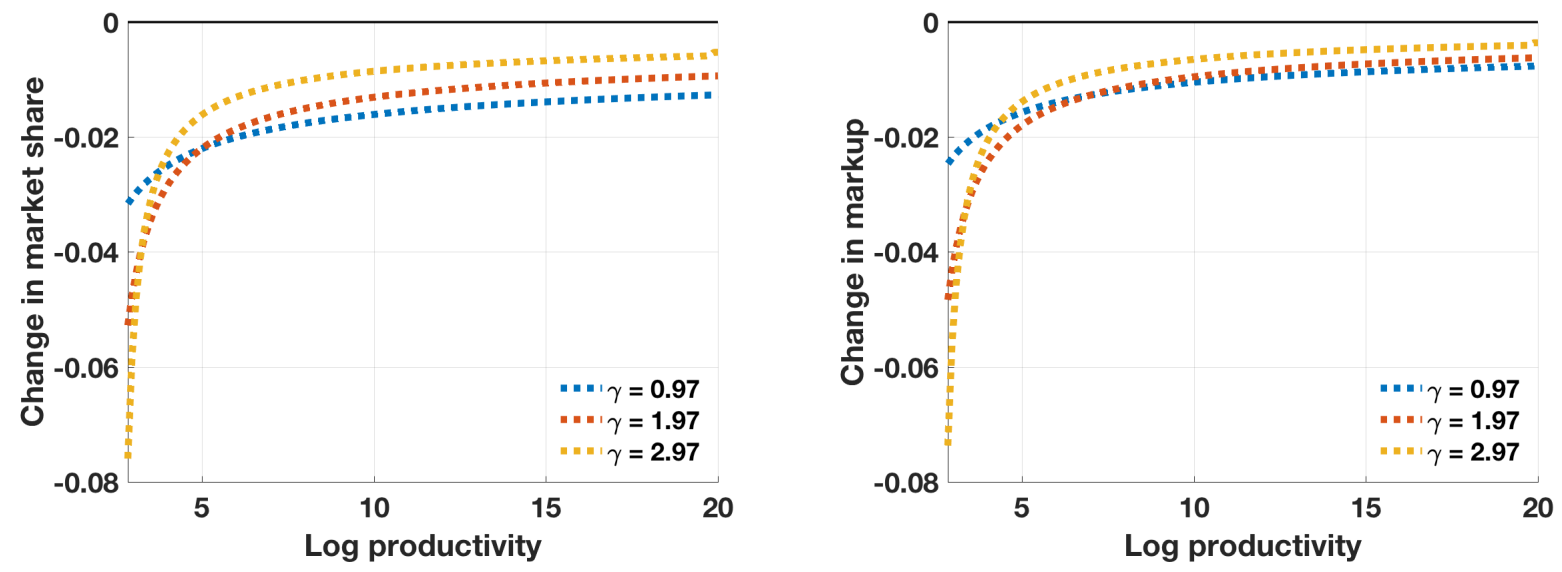

The figure plots the change in the market share and markup of each firm as a function of its idiosyncratic productivity following a decrease in entry $\operatorname{costs} f_{e}$ and for different values of $\gamma$. The higher is $\gamma$, the stronger is the reallocation of production towards the most productive firms, but the weaker the reduction in markup following a decrease in market shares. 
The role of the Pareto shape parameter, $\alpha$. In Figure 3 we show how the response of aggregate employment to the reform also depends on the initial dispersion of productivity. In particular, the more dispersed is the initial productivity distribution, for a given $\gamma$, the stronger is the overall increase in employment. This is due to a stronger reallocation of production towards high productivity firms, which further reduces the price level, and so further stimulates labor supply. That is, the reform improves the initial misallocation of resources across operating firms, induced by the heterogeneity of markups. In particular, the high productivity firms are under producing in the translog model. ${ }^{26}$. Since the level of initial misallocation is increasing in the level of productivity dispersion $(1 / \alpha)$, the reallocation power induced by a rise in competition is stronger if dispersion is higher. ${ }^{27}$

Figure 3: Impact of a Decrease in $f_{e}$ on Firms' Labor Demand for different values of $\alpha$
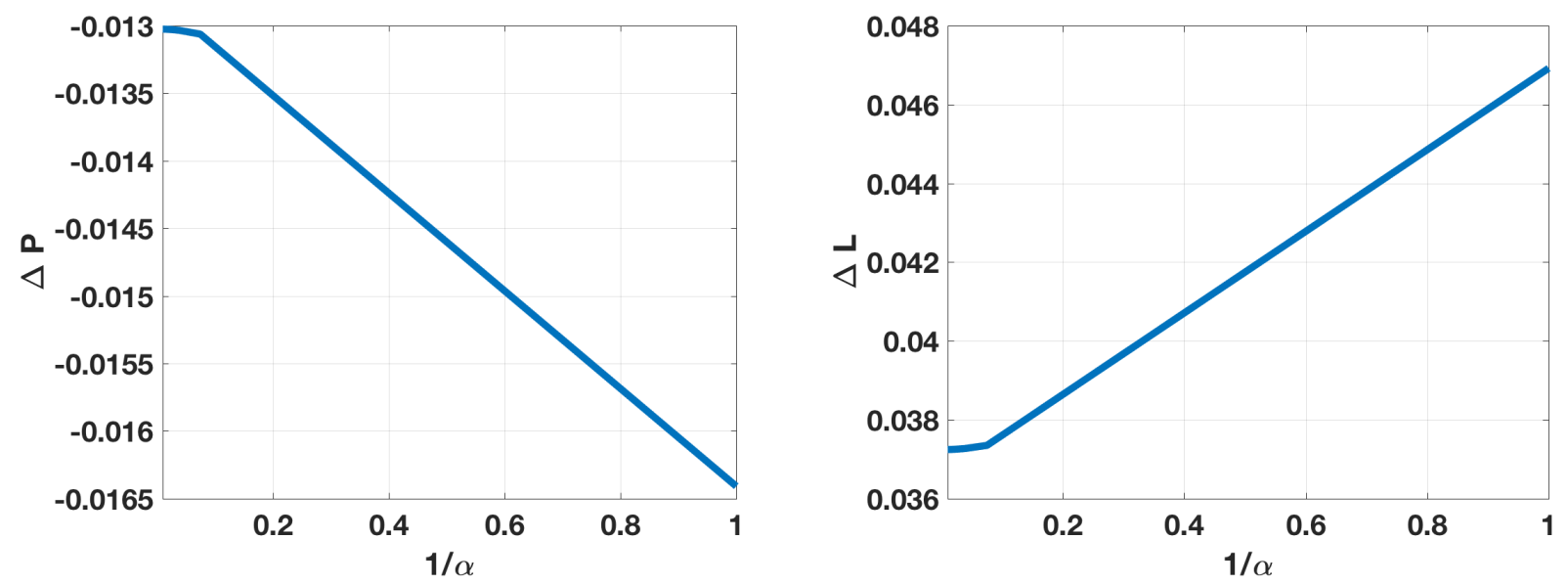

The figures plot the impact of the reform on the aggregate price level $P$, and on aggregate employment $L$ as a function of the dispersion in the initial distribution of idiosyncratic productivities. In particular, the aggregate impact of the reform is stronger when the initial productivity distribution is more dispersed; this is due to a stronger reallocation of production towards more productive firms, which charge lower prices. This in turn strengthens the increase of aggregate employment.

\footnotetext{
${ }^{26}$ To see why markup dispersion leads to misallocation in equilibrium see Baqaee and Farhi 2017; Edmond et al. 2018.

${ }^{27}$ Note also that the increase in aggregate labor $L$ as a function of the initial productivity distribution is stronger for higher $\gamma$, that is, the more homogeneous is the initial distribution of markups across firms of different productivities.
} 


\subsection{Assessing the economy-wide impact of the reform}

Following our empirical results, the theoretical analysis so far has targeted and studied the implications of the reform on a local aggregation of employment. In the empirical analysis, we claimed that the local increase in employment was an upper bound for the economy-wide impact of the reform. The labor supply elasticity is higher at the municipality level, because workers can commute across municipalities. Moreover, since our dataset only considers firms in the private sector, the measured labor supply is further raised by the fact that we cannot control for workers moving away from government-owned firms within each municipality.

The purpose of this exercise is to use the model to understand the economy-wide impact of the reform. We do so by running a comparative statics exercise on $\nu$. In particular we show how firm-level and aggregate employment response changes when we consider lower values of $\nu$, which are closer to the values measured in the literature on the macro labor supply elasticity. This is shown in Figure 4 and Table 4 . Note that the lower the labor supply elasticity the weaker the impact of the reform on firm-level and aggregate employment. In addition, as already shown with the comparative statics exercise on $\gamma$, Table 4 illustrates that relative contribution of incumbents falls when the overall increase in employment is lower. In particular, the contributions of incumbents is negative when labor supply elasticity is equal to zero, because a share of the fixed labor force can only shift to entrants.

Table 4: Response of Aggregate Employment and Contribution of Entrants and Incumbents for Different $\nu$

\begin{tabular}{|l|c|c|}
\hline & $\boldsymbol{\nu}=\mathbf{1}$ & $\boldsymbol{\nu}=\mathbf{2 . 8 6}$ \\
\hline $\boldsymbol{\Delta} \boldsymbol{L}-$ Total & $1.67 \%$ & $4.84 \%$ \\
$\% \boldsymbol{\Delta} \boldsymbol{L}-$ Entrants & $134 \%$ & $46.3 \%$ \\
$\% \boldsymbol{\Delta} \boldsymbol{L}-$ Incumbents & $-34 \%$ & $53.7 \%$ \\
\hline
\end{tabular}

The Table computes the total increase in employment and the underlying contribution of entrants and incumbents for different values of $\nu$. The results in the second and third row refer to the share of the overall change in employment accruing to entrants and incumbent firms.

\section{Conclusion}

In this paper we provide novel evidence on the macroeconomic impact and firm-level channels of a reform that reduced entry costs for firms and increased business competition. We do so by using an economy-wide entry deregulation reform in Portugal as a natural experiment. The reform led to an increase in firm entry and aggregate employment. We then uncover the 
Figure 4: Impact of an Decrease in $f_{e}$ on Firms' Labor Demand for different values of $\nu$

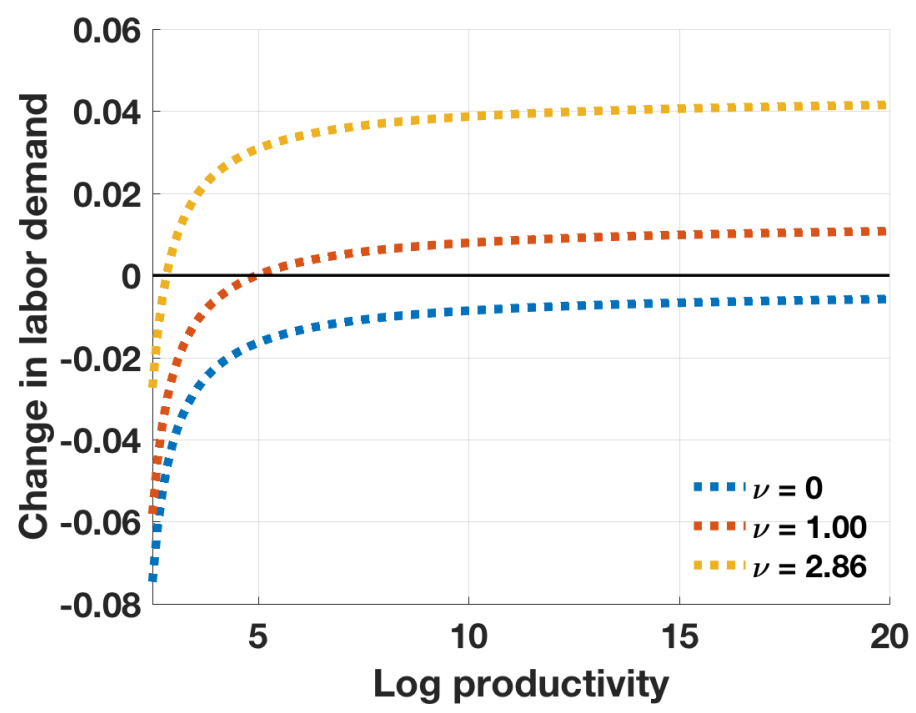

The figure plots the change in the labor demand of each firm as a function of its idiosyncratic productivity following a decrease in entry $\operatorname{costs} f_{e}$ for different values of $\nu$. Higher values of $\nu$ increase the employment response for firms of all productivity levels. This is because, for a given decline in the aggregate price level $P$, aggregate labor supply expands by more.

mechanisms underlying the response of employment. We find that the bulk of employment expansion is coming from incumbent firms increasing their size. Moreover, the response of incumbent firms is heterogeneous. In particular, the expansion is driven by those who were the most productive before the reform.

We show that models with heterogeneous firms and CES demand deliver predictions that are inconsistent with our evidence on the response of incumbent firms. Accordingly, these models predict that all of them would reduce their employment by the same amount, regardless of their idiosyncratic productivity. We then present a model with heterogeneous firms and variable markups that delivers predictions that are consistent with the empirical evidence. The model assumes symmetric translog demand as in Feenstra (2003), such that the elasticity of substitution increases with a higher mass of available goods, and the demand elasticity of each firm decreases with its level of productivity.

A key result from our model is that the response of labor demand for each firm depends on the firm's idiosyncratic productivity. In particular, the most productive incumbents expand their size in response to more entry. This is because, on the one hand, they face a lower demand elasticity, which allows them to lose a smaller market share following entry of new firms, for a given size of the economy. On the other hand, since the rise in entry lowers the 
aggregate price level and stimulates labor supply, the reform increases aggregate demand for each firm, such that the most productive incumbents on net expand their level of output and employment relative to the pre-reform period.

The Portuguese experiment allows us to identify the impact of the reform. However, a concern can be raised about the external validity of our results. Evidence of no change in the exit probability or no downward adjustment in the size of the least productive incumbents may be related to rigidities specific to the Portuguese economy. Another possibility is that evidence on these facts requires a longer time coverage of the post-reform period.

However, the key takeaways from this paper hold beyond the Portuguese setting. Specifically, we believe that quantitative models used to inform policy-making on reforms that change the competitive environment or the number of operating firms, should be modified to allow for firm heterogeneity and variable markups. 


\section{References}

Aghion, P., Blundell, R., Griffith, R., Howitt, P. and Prantl, S. (2009). The effects of entry on incumbent innovation and productivity. The Review of Economics and Statistics, 91 20-32.

Aghion, P., Burgess, R., Redding, S. and Zilibotti, F. (2005). Entry liberalization and inequality in industrial performance. Journal of the European Economic Association, 3 291-302.

Alon, T., Berger, D., Dent, R. and Pugsley, B. (2018). Older and slower: The startup deficit?s lasting effects on aggregate productivity growth. Journal of Monetary Economics, 93 68-85.

Arkolakis, C., Costinot, A., Donaldson, D. and Rodríguez-Clare, A. (2018). The elusive pro-competitive effects of trade. The Review of Economic Studies, 86 46-80.

Atkeson, A. and Burstein, A. (2008). Pricing-to-market, trade costs, and international relative prices. American Economic Review, 98 1998-2031.

Bajgar, M., Berlingieri, G., Calligaris, S., Criscuolo, C. and Timmis, J. (2019). Industry concentration in europe and north america.

Baqaee, D. R. and Farhi, E. (2017). Productivity and misallocation in general equilibrium. Tech. rep., National Bureau of Economic Research.

Betrand, M. and Kramarz, F. (2002). Does entry regulation hinder job creation?evidence from the french retail industry. "Quarterly Journal of Economics, 117 1369-1414.

Bilbiie, F., Ghironi, F. and Melitz, M. J. (2012). Endogenous entry, product variety, and business cycles. Journal of Political Economy, 120.

Blanchard, O. (2007). Adjustment within the euro. the difficult case of portugal. Portuguese Economic Journal, 6 1-21.

Blanchard, O. and Giavazzi, F. (2003). Macroeconomic effects of regulation and deregulation in goods and labor markets. The Quarterly journal of economics, 118 879-907.

Bouis, R., Duval, M. R. A. and Eugster, J. (2016). Product Market Deregulation and Growth: New Country-Industry-Level Evidence. International Monetary Fund. 
Branstetter, L., Lima, F., Taylor, L. J. and Venâncio, A. (2014). Do entry regulations deter entrepreneurship and job creation? evidence from recent reforms in portugal. The Economic Journal, 124 805-832.

Cacciatore, M., Duval, R., Fiori, G. and Ghironi, F. (2016a). Market reforms in the time of imbalance. Journal of Economic Dynamics and Control, 72 69-93.

Cacciatore, M., Duval, R., Fiori, G. and Ghironi, F. (2016b). Short-term pain for long-term gain: Market deregulation and monetary policy in small open economies. Journal of International Money and Finance, 68 358-385.

Cacciatore, M., Duval, R., Fiori, G. and Ghironi, F. (2017). Market reforms at the zero lower bound. Tech. rep., National Bureau of Economic Research.

Cacciatore, M. and Fiori, G. (2016). The macroeconomic effects of goods and labor markets deregulation. Review of Economic Dynamics, 20 1-24.

Cacciatore, M., Fiori, G. and Ghironi, F. (2016c). Market deregulation and optimal monetary policy in a monetary union. Journal of International Economics, 99 120-137.

Clementi, G. L. and Palazzo, B. (2016). Entry, exit, firm dynamics, and aggregate ffuctuations. American Economic Journal: Macroeconomics, 8 1-41.

Colciago, A. (2018). Structural reforms and endogenous market structures. In Structural Reforms. Springer, 199-219.

Decker, R., Haltiwanger, J., Jarmin, R. and Miranda, J. (2014). The role of entrepreneurship in us job creation and economic dynamism. Journal of Economic Perspectives, $283-24$.

Duval, R. and Furceri, D. (2018). The effects of labor and product market reforms: the role of macroeconomic conditions and policies. IMF Economic Review, 66 31-69.

Edmond, C., Midrigan, V. and Xu, D. Y. (2015). Competition markups, and the gains from international trade. American Economic Review, 105 3183-3221.

Edmond, C., Midrigan, V. and Xu, D. Y. (2018). How costly are markups? Tech. rep., National Bureau of Economic Research.

Eggertsson, G., Ferrero, A. and Raffo, A. (2014). Can structural reforms help europe? Journal of Monetary Economics, 61 2-22.

EgGertsson, G. B. (2012). Was the new deal contractionary? American Economic Review, 102(1) $524-555$. 
Feenstra, R. C. (2003). A homothetic utility function for monopolistic competition models, without constant price elasticity. Economics Letters, 78 79-86.

Gourio, F., Messer, T. and Siemer, M. (2016). Firm entry and macroeconomic dynamics: a state-level analysis. American Economic Review, 106 214-18.

Greenwood, J., Hercowitz, Z. and Huffman, G. W. (1988). Investment, capacity utilization, and the real business cycle. The American Economic Review 402-417.

Grullon, G., Larkin, Y. and Michaely, R. (2018). Are us industries becoming more concentrated? Forthcoming, Review of Finance.

Gutiérrez, G. and Philippon, T. (2017). Declining competition and investment in the us. Tech. rep., National Bureau of Economic Research.

Haltiwanger, J., Jarmin, R. S. and Miranda, J. (2013). Who creates jobs? small versus large versus young. Review of Economics and Statistics, 95 347-361.

Hathaway, I. and Litan, R. E. (2014). Declining business dynamism in the united states: A look at states and metros. Brookings Institution 2.

Hombert, J., Schoar, A., Sraer, D. and Thesmar, D. (2014). Can unemployment insurance spur entrepreneurial activity? Tech. rep., National Bureau of Economic Research.

Hopenhayn, H. A. (1992). Entry, exit, and firm dynamics in long-run equilibrium. Econometrica: Journal of the Econometric Society 1127-1150.

Kaplan, D. S., Piedra, E. and Seira, E. (2011). Entry regulation and business start-ups: Evidence from mexico. Journal of Public Economics, 95 1501-1515.

Lee, Y. and Mukoyama, T. (2008). Entry, exit and plant-level dynamics over the business cycle.

Leitão Marques, M. M. (2007). One-stop shopping in portugal. World Bank, Smart Lessons in Advisory Services.

Melitz, M. J. (2003). The impact of trade on intra-industry reallocations and aggregate industry productivity. Econometrica, 71 1695-1725.

Pugsley, B. W. and Sahin, A. (2018). Grown-up business cycles. The Review of Financial Studies, 32 1102-1147.

SEDlÁCEK, P. (2014). Lost generations of firms and aggregate labor market dynamics. Tech. rep., Tech. rep., WP. 
Viviano, E. (2008). Entry regulations and labour market outcomes: Evidence from the italian retail trade sector. Labour Economics, 15 1200-1222.

Zhelobodko, E., Kokovin, S., Parenti, M. and Thisse, J.-F. (2012). Monopolistic competition: Beyond the constant elasticity of substitution. Econometrica, 80 2765-2784. 


\section{Figures and Tables}

Table 5: One-Stop Shop Program Implementation

\begin{tabular}{ccccccc}
\hline & $\mathbf{2 0 0 5}$ & $\mathbf{2 0 0 6}$ & $\mathbf{2 0 0 7}$ & $\mathbf{2 0 0 8}$ & $\mathbf{2 0 0 9}$ & Total \\
\hline Number of shops & 20 & 28 & 31 & 36 & 49 & 164 \\
Number of counties implementing & 13 & 24 & 28 & 34 & 46 & 145 \\
Number of counties $>$ 1 shop & 6 & 3 & 1 & 2 & 0 & 12 \\
\hline
\end{tabular}

Source: Branstetter et al. (2014) based on publicly available calendar data provided by the Instituto dos Registos e Notariado.

Figure 5: Timing of the Opening of One-Stop Shops across the Country
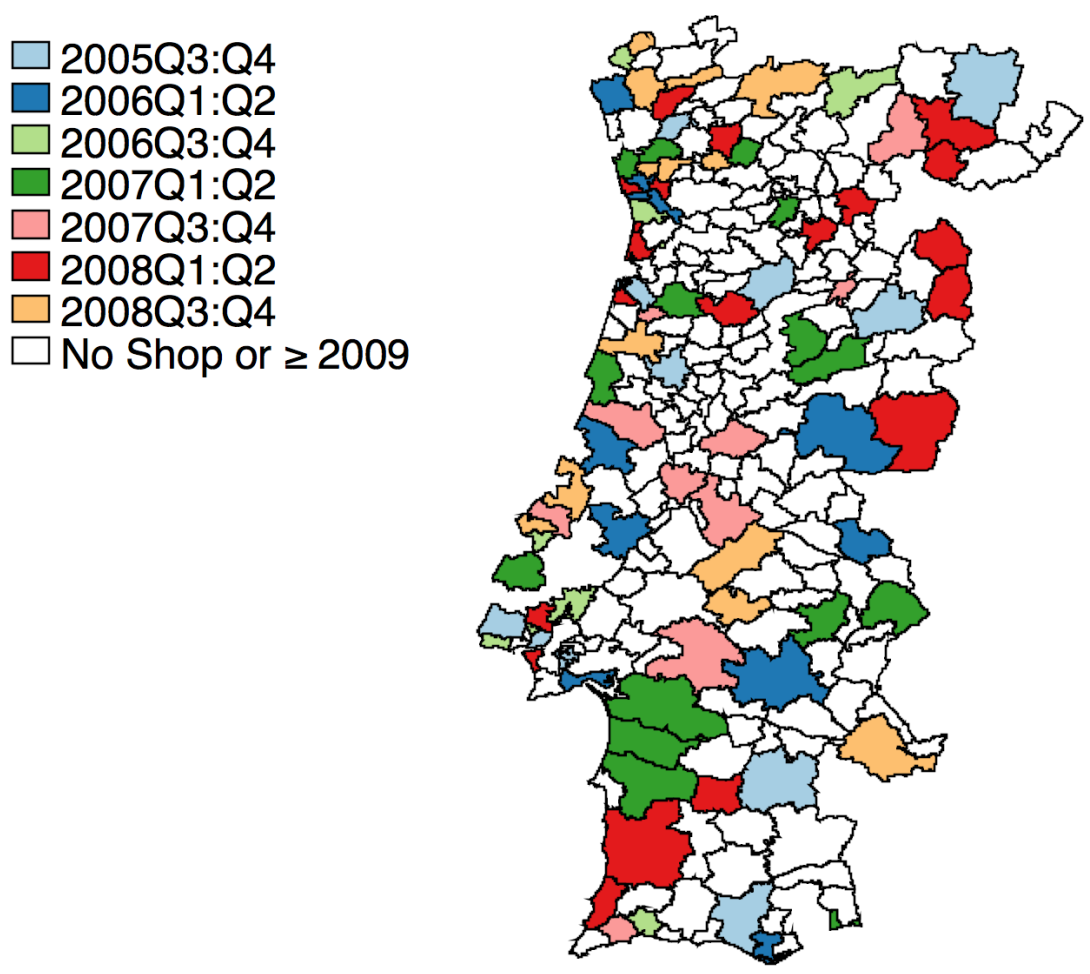

Source: Instituto dos Registos e Notariado.

The figure shows the pattern of opening of the One-Stop Shops across the Portuguese municipalities. 
Table 6: Descriptive Statistics on Municipality Groups in the Pre-Reform Period

\begin{tabular}{|c|c|c|c|c|}
\hline & Treated Municipalities & Never-Treated & Early-Treated & Late-Treated \\
\hline \multicolumn{5}{|l|}{ Firm Demographics } \\
\hline Entry rate & $\begin{array}{c}8.5 \%(4.6 \%) \\
{[5.7 \%, 10.2 \%]}\end{array}$ & $\begin{array}{c}9.4 \%(6.9 \%) \\
{[5.4 \%, 11.9 \%]}\end{array}$ & $\begin{array}{c}7.9 \%(4 \%) \\
{[5.8 \%, 8.7 \%]}\end{array}$ & $\begin{array}{c}8.8 \%(5 \%) \\
{[5.6 \%, 10.8 \%]}\end{array}$ \\
\hline Entrants x 1,000 inhab & $\begin{array}{c}0.83(0.4) \\
{[0.56,1.02]}\end{array}$ & $\begin{array}{l}0.71(0.45) \\
{[0.4,0.97]}\end{array}$ & $\begin{array}{l}0.88(0.34) \\
{[0.64,1.03]}\end{array}$ & $\begin{array}{l}0.81(0.42) \\
{[0.54,1.01]}\end{array}$ \\
\hline Exit rate & $\begin{array}{l}8.4 \%(2.8 \%) \\
{[6.8 \%, 10 \%]}\end{array}$ & $\begin{array}{l}7.7 \%(4.1 \%) \\
{[5.3 \%, 10 \%]}\end{array}$ & $\begin{array}{l}8.5 \%(2.3 \%) \\
{[7 \%, 9.7 \%]}\end{array}$ & $\begin{array}{c}8.3 \%(3 \%) \\
{[6.6 \%, 9.9 \%]}\end{array}$ \\
\hline Exit x 1,000 inhab & $\begin{array}{c}0.93(0.38) \\
{[0.67,1.1]}\end{array}$ & $\begin{array}{c}0.68(0.4) \\
{[0.38,0.94]}\end{array}$ & $\begin{array}{l}1.1(0.39) \\
{[0.8,1.3]}\end{array}$ & $\begin{array}{c}0.84(0.35) \\
{[0.6,1.1]}\end{array}$ \\
\hline Active firms x 1,000 inhab & $\begin{array}{c}10.67(3.8) \\
{[8.1,12.9]}\end{array}$ & $\begin{array}{l}8.32(3.4) \\
{[5.7,10.4]}\end{array}$ & $\begin{array}{l}12.21(3.8) \\
{[9.4,15.1]}\end{array}$ & $\begin{array}{c}9.8(3.5) \\
{[7.4,11.7]}\end{array}$ \\
\hline \multicolumn{5}{|c|}{ Macroeconomic Characteristics } \\
\hline Employment rate (Census) & $\begin{array}{c}47.2 \%(24 \%) \\
{[34.4 \%, 59.2 \%]}\end{array}$ & $\begin{array}{c}34.1 \%(21 \%) \\
{[25.8 \%, 44.3 \%]}\end{array}$ & $\begin{array}{c}53.7 \%(27 \%) \\
{[39.8 \%, 65.7 \%]}\end{array}$ & $\begin{array}{c}43.4 \%(18 \%) \\
{[30.6 \%, 54.9 \%]}\end{array}$ \\
\hline Residents (mean) & $\begin{array}{c}66,896.1(128,244) \\
{[17,852,74,965]}\end{array}$ & $\begin{array}{c}18,540,7(41,762.5) \\
{[6,396,21,135]}\end{array}$ & $\begin{array}{c}114,213.3(149,881.3) \\
{[44,162,142,728]}\end{array}$ & $\begin{array}{c}39,421.6(56,260.2) \\
{[14,241,52,604]}\end{array}$ \\
\hline Share of pop aged 65 or more & $\begin{array}{c}19.07 \%(6.5 \%) \\
{[14.3 \%, 22.3 \%]}\end{array}$ & $\begin{array}{l}22.05 \%(8.2 \%) \\
{[17.3 \%, 26.3 \%]}\end{array}$ & $\begin{array}{c}16.31 \%(3.99 \%) \\
{[12.9 \%, 19.9 \%]}\end{array}$ & $\begin{array}{l}20.7 \%(7.21 \%) \\
{[16.2 \%, 24.7 \%]}\end{array}$ \\
\hline \multicolumn{5}{|l|}{ Macro-Sector of Activity } \\
\hline Agriculture - Sales & $\begin{array}{c}2.82 \%(6 \%) \\
{[0.1 \%, 2.8 \%]}\end{array}$ & $\begin{array}{c}3.9 \%(6 \%) \\
{[0.4 \%, 5.2 \%]}\end{array}$ & $\begin{array}{c}1.37 \%(4 \%) \\
{[0.1 \%, 1.3 \%]}\end{array}$ & $\begin{array}{c}3.67 \%(6 \%) \\
{[0.2 \%, 3.8 \%]}\end{array}$ \\
\hline Manufacturing - Sales & $\begin{array}{c}28.3 \%(19 \%) \\
{[11.1 \%, 40.5 \%]}\end{array}$ & $\begin{array}{c}27.2 \%(20 \%) \\
{[11.7 \%, 40.4 \%]}\end{array}$ & $\begin{array}{c}28.2 \%(20 \%) \\
{[14.3 \%, 45.4 \%]}\end{array}$ & $\begin{array}{c}28.3 \%(20 \%) \\
{[10.9 \%, 40.5 \%]}\end{array}$ \\
\hline Construction - Sales & $\begin{array}{c}12.1 \%(9 \%) \\
{[5.3 \%, 14.6 \%]}\end{array}$ & $\begin{array}{l}16.9 \%(13 \%) \\
{[7.2 \%, 22 \%]}\end{array}$ & $\begin{array}{c}10.4 \%(7 \%) \\
{[6.2 \%, 12.7 \%]}\end{array}$ & $\begin{array}{l}13.1 \%(10 \%) \\
{[4.8 \% 16.6 \%]}\end{array}$ \\
\hline Services - Sales & $\begin{array}{l}46.66 \%(19 \%) \\
{[42.5 \%, 70.1 \%]}\end{array}$ & $\begin{array}{l}41.13 \%(15 \%) \\
{[39.6 \%, 65.3 \%]}\end{array}$ & $\begin{array}{l}53.76 \%(17 \%) \\
{[43.9 \%, 73.5 \%]}\end{array}$ & $\begin{array}{c}41.92 \%(16 \%) \\
{[42 \%, 66.2 \%]}\end{array}$ \\
\hline
\end{tabular}

Source: Quadros de Pessoal and Portugal National Statistics Institute.

The Table displays the mean of each variable. Standard deviations are in round parenthesis. The $25^{t h}$ and $75^{t h}$ percentiles are in square parenthesis. The statistics refer to the period 2000-2004. 
Table 7: Descriptive Statistics on Non-Financial Corporations

\begin{tabular}{|c|c|c|c|c|c|c|c|}
\hline & \multicolumn{7}{|c|}{ yearly average } \\
\hline \multicolumn{8}{|l|}{ Relevant Statistics } \\
\hline Entry Rate & \multicolumn{7}{|c|}{$7.5 \%$} \\
\hline Exit Rate & \multicolumn{7}{|c|}{$9.3 \%$} \\
\hline Operating Firms & \multicolumn{7}{|c|}{125,015} \\
\hline \multicolumn{8}{|l|}{ Employment Sector Shares } \\
\hline Agriculture & \multicolumn{7}{|c|}{$1.63 \%$} \\
\hline Manufacturing & \multicolumn{7}{|c|}{$32.6 \%$} \\
\hline Construction & \multicolumn{7}{|c|}{$15.13 \%$} \\
\hline Services & \multicolumn{7}{|c|}{$50.64 \%$} \\
\hline \multicolumn{8}{|l|}{ Sales Sector Shares } \\
\hline Agriculture & \multicolumn{7}{|c|}{$1.52 \%$} \\
\hline Manufacturing & \multicolumn{7}{|c|}{$26.6 \%$} \\
\hline Construction & \multicolumn{7}{|c|}{$10.14 \%$} \\
\hline \multirow[t]{2}{*}{ Services } & \multicolumn{7}{|c|}{$61.74 \%$} \\
\hline & & $p 1$ & $p 25$ & $p 50$ & mean & $p 75$ & $p 99$ \\
\hline \multicolumn{8}{|l|}{ Relevant Distributions } \\
\hline Size Distribution & & 1 & 2 & 4 & 7.13 & 8 & 55 \\
\hline Age Distribution & & 0 & 2 & 6 & 10.87 & 15 & 59 \\
\hline Size of Entrants & & 1 & 1 & 2 & 3.75 & 4 & 27 \\
\hline Size of Young Firms ( $\leq 5 \mathrm{yrs})$ & & 1 & 2 & 3 & 4.95 & 5 & 36 \\
\hline \multirow[t]{2}{*}{ Size of Old Firms } & & 1 & 3 & 5 & 8.96 & 10 & 64 \\
\hline & Entrants & Age $0-2$ & $3-5$ & $6-15$ & $15+$ & Young Firms & Old Firms \\
\hline \multicolumn{8}{|c|}{ Average Statistics by Age Groups } \\
\hline Municipality Sales Share & $2.5 \%$ & $13.7 \%$ & $16.2 \%$ & $37.7 \%$ & $34 \%$ & $29.7 \%$ & $70.3 \%$ \\
\hline Municipality Employment Share & $5 \%$ & $14.4 \%$ & $17.8 \%$ & $35.6 \%$ & $28.7 \%$ & $36.9 \%$ & $63.1 \%$ \\
\hline Municipality Exit Share & $12.5 \%$ & $43.2 \%$ & $23.7 \%$ & $23.3 \%$ & $10.3 \%$ & $66.7 \%$ & $33.3 \%$ \\
\hline \multicolumn{8}{|l|}{ Municipality Count Firm Share } \\
\hline Size & 3.75 & 4.42 & 5.7 & 7.71 & 10.5 & 4.9 & 9 \\
\hline Exit Rate & $16.6 \%$ & $15.7 \%$ & $11.4 \%$ & $7.45 \%$ & $5.4 \%$ & $13.9 \%$ & $6.5 \%$ \\
\hline 2-yr Survival Rate Entrants & $69.7 \%$ & & & & & & \\
\hline 4-yr Survival Rate Entrant & $46.6 \%$ & & & & & & \\
\hline
\end{tabular}

Source: Quadros de Pessoal

The statistics refer to the period 2000-2008. 
Figure 6: Impact of Empresa Na Hora on Aggregate Local Firm Creation

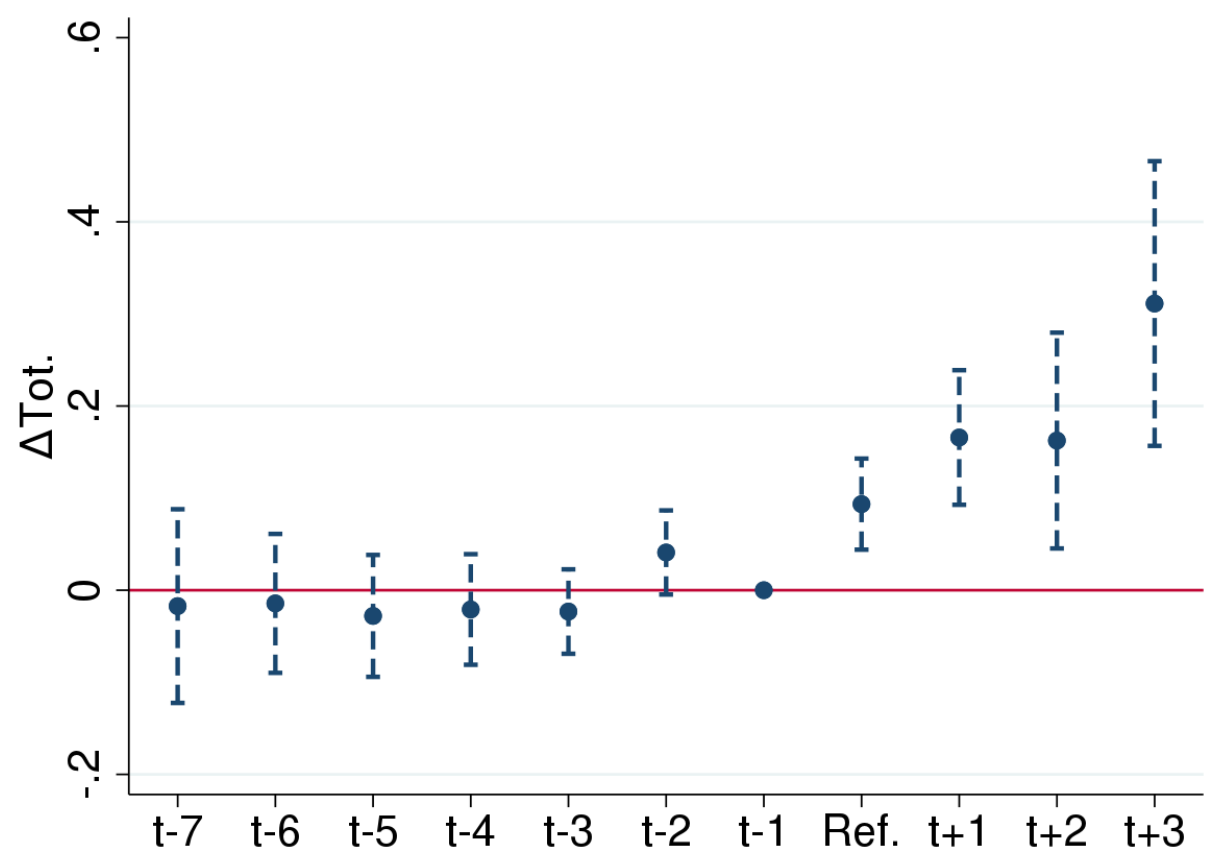

The figure shows the estimates of $\beta_{\tau}$ from the following regression at the municipality level:

$$
y_{m, t}=\alpha_{m}+\delta_{t}+\sum_{\tau=-7}^{\tau=3} \beta_{\tau} \mathbb{1}\left(t-\tau_{0, m}=\tau\right)+\sum_{m} \gamma_{m} \mathbb{1}\left(\text { Municipality }_{m}=1\right) t+\epsilon_{m, t},
$$

where $y_{m, t}=$ total entrants per 1,000 residents, $\tau_{0, m}$ corresponds to the year in which the One-Stop Shop opened in municipality $m$ and $\gamma$ is a vector of coefficients for municipalityspecific trends. Standard errors are clustered at the municipality level. $90 \%$ confidence intervals. 
Figure 7: Impact of Empresa na Hora on Aggregate Local Employment

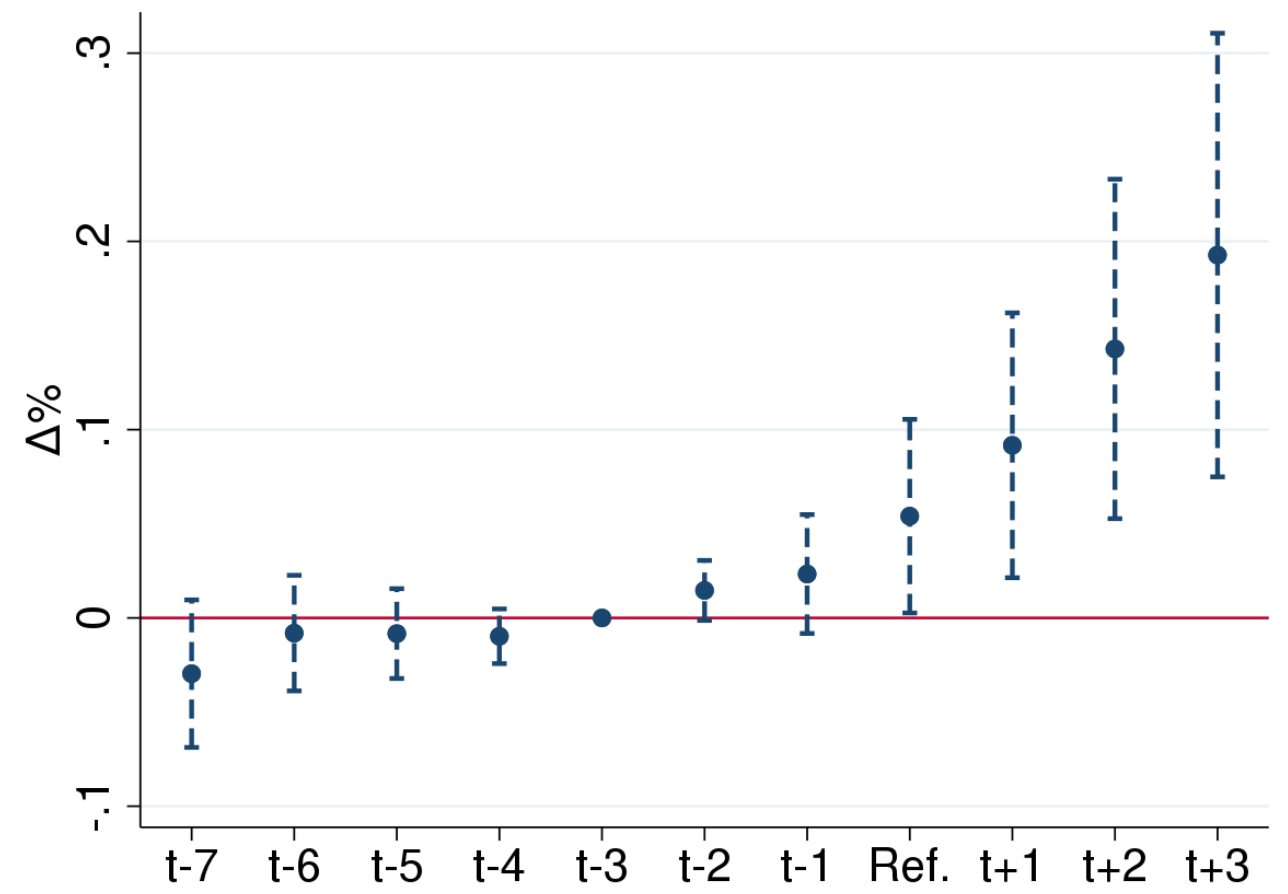

The figure shows estimates of $\beta_{\tau}$ from the following regression with municipality-level aggregates:

$$
y_{m, t}=\alpha_{m}+\delta_{t}+\sum_{\tau=-7}^{\tau=3} \beta_{\tau} \mathbb{1}\left(t-\tau_{0, m}=\tau\right)+\sum_{m} \gamma_{m} \mathbb{1}\left(\text { Municipality }_{m}=1\right) t+\epsilon_{m, t},
$$

where $y_{m, t}=\log$ (total employment per 1,000 residents), $\tau_{0, m}$ corresponds to the year in which the One-Stop Shop opened in municipality $m$ and $\gamma$ is a vector of coefficients for municipalityspecific trends. Standard errors are clustered at the municipality level. $90 \%$ confidence intervals. 
Figure 8: Impact of Empresa na Hora on Employment by Age Groups

Age 0-5

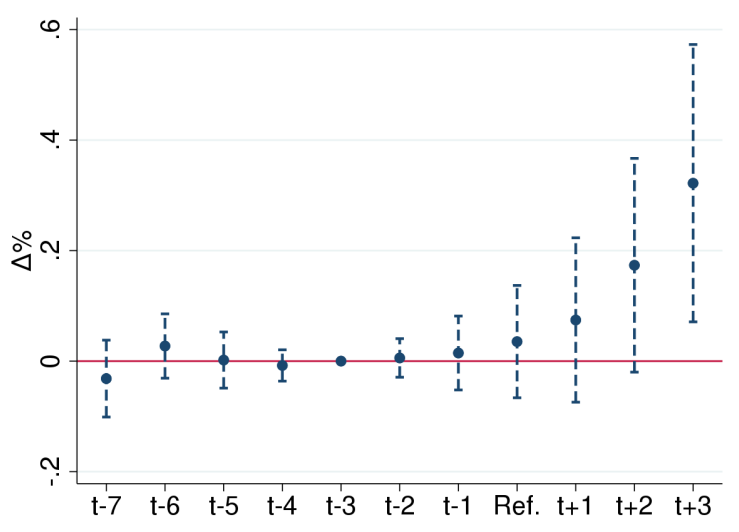

Age 6-15

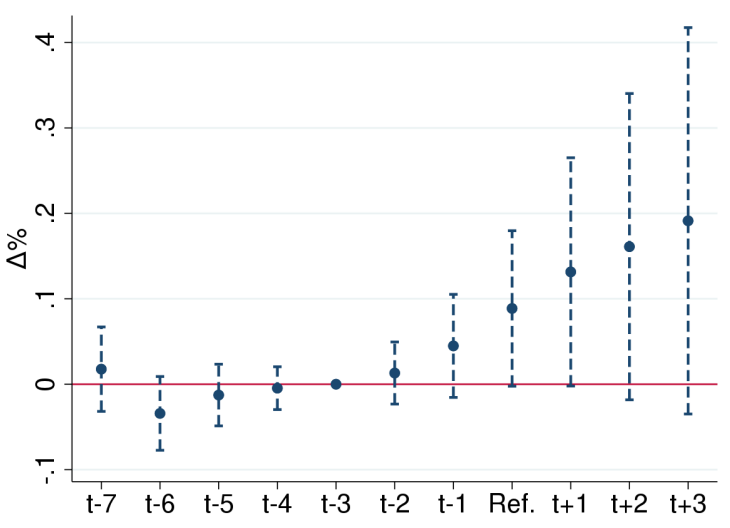

Age $15+$

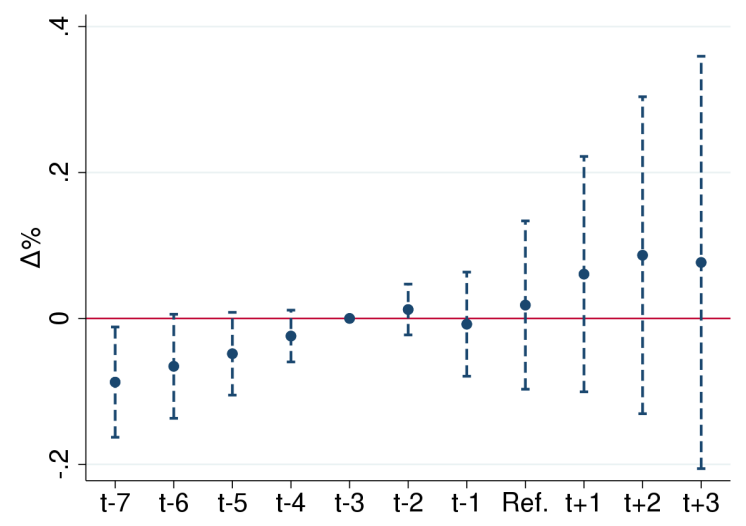

The figures show the estimates of $\beta_{\tau}$ from the following regression with municipality-level aggregates:

$$
y_{m, t}=\alpha_{m}+\delta_{t}+\sum_{\tau=-7}^{\tau=3} \beta_{\tau} \mathbb{1}\left(t-\tau_{0, m}=\tau\right)+\sum_{m} \gamma_{m} \mathbb{1}\left(\text { Municipality }_{m}=1\right) t+\epsilon_{m, t},
$$

where $y_{m, t}=$ total employment per 1,000 residents by the different age groups, $\tau_{0, m}$ corresponds to the year in which the One-Stop Shop opened in municipality $m$ and $\gamma$ is a vector of coefficients for municipality-specific trends. Standard errors are clustered at the municipality level. $90 \%$ confidence intervals. 
Figure 9: Impact of Empresa na Hora on Average Size by Age Groups

Age 0-5

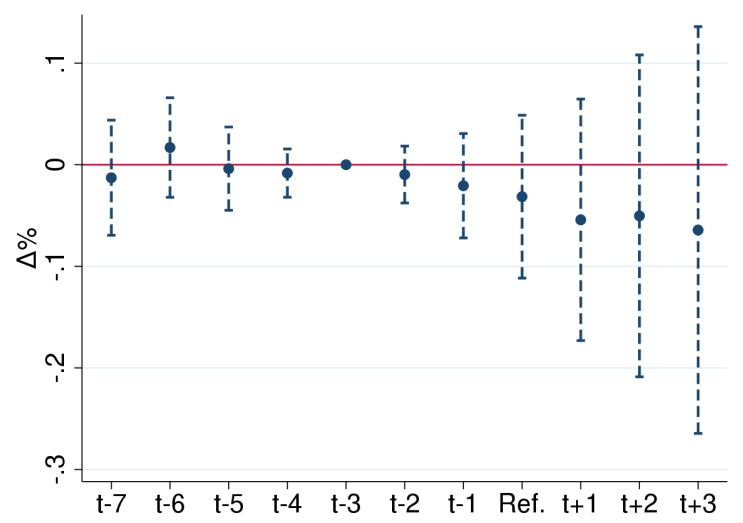

Age 6-15

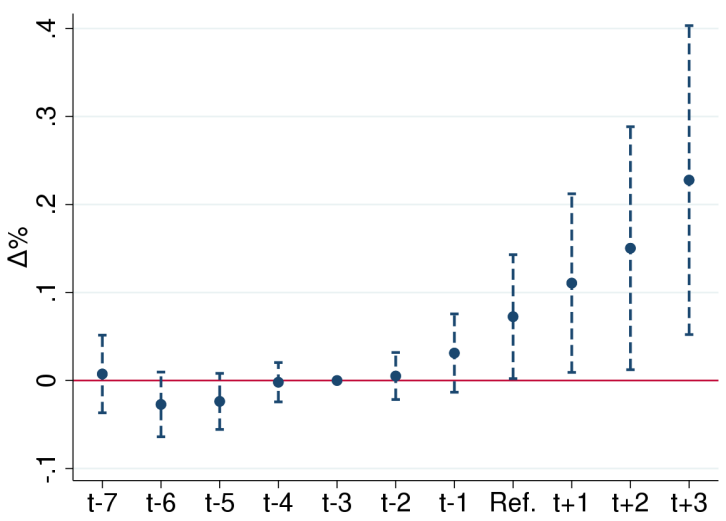

Age $15+$

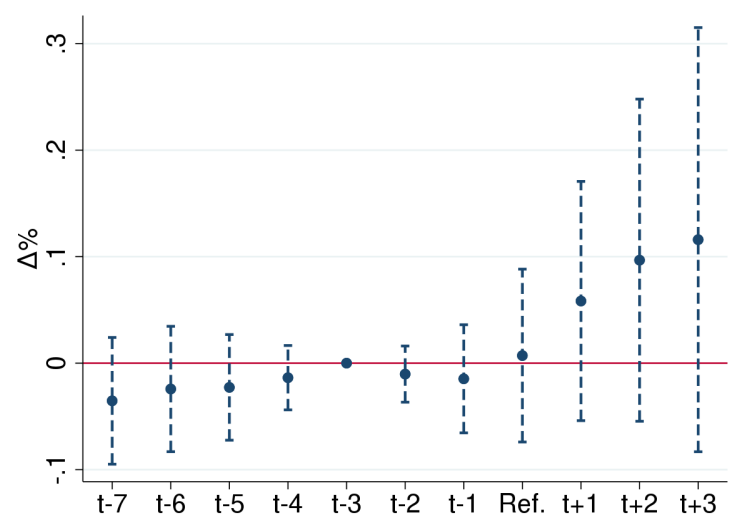

The figures show the estimates of $\beta_{\tau}$ from the following regression with municipality-level aggregates:

$$
y_{m, t}=\alpha_{m}+\delta_{t}+\sum_{\tau=-7}^{\tau=3} \beta_{\tau} \mathbb{1}\left(t-\tau_{0, m}=\tau\right)+\sum_{m} \gamma_{m} \mathbb{1}\left(\text { Municipality }_{m}=1\right) t+\epsilon_{m, t}
$$

where $y_{m, t}=$ average size $=\frac{\text { Tot. Employment }}{\text { Tot. Firms }}$ for the different age groups, $\tau_{0, m}$ corresponds to the year in which the One-Stop Shop opened in municipality $m$ and $\gamma$ is a vector of coefficients for municipality-specific trends. Standard errors are clustered at the municipality level. $90 \%$ confidence intervals. 
Figure 10: Impact on Exit Probability by Age Groups

Panel (a)

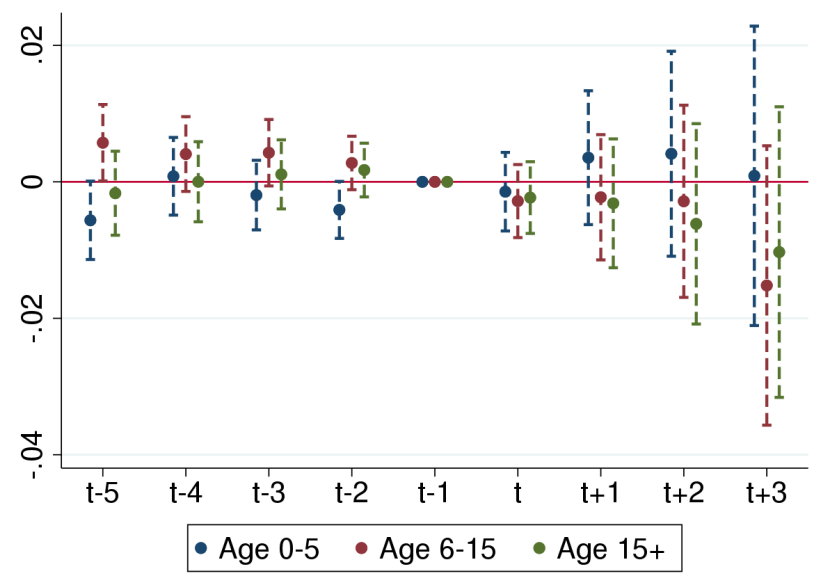

Panel (b)

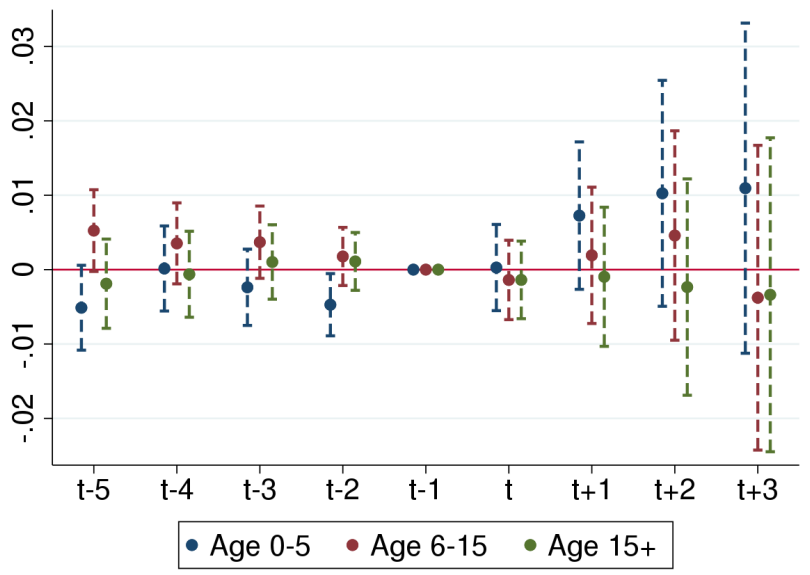

The figures show estimates of $\beta_{\tau}$ from the following regression at the firm level that we run for each age group (age $0-5,6-15,15+$ ):

$$
\operatorname{Pr}\left(\text { exit }_{i t}\right)=\alpha_{m}+\delta_{t}+\sum_{\tau=-7}^{\tau=3} \beta_{\tau} \mathbb{1}\left(t-\tau_{0, m}=\tau\right)+\sum_{m} \gamma_{m} \mathbb{1}\left(\text { Municipality }_{m}=1\right) t+\epsilon_{i, t}
$$

where $\alpha_{m}$ and $\delta_{t}$ are municipality and year fixed effects, respectively. $\tau_{0, m}$ corresponds to the year in which the One-Stop Shop opened in municipality $m$ and $\gamma$ is a vector of coefficients for municipality-specific trends. Standard errors are clustered at the municipality level. $90 \%$. confidence intervals. In Panel (b) we also allow for a 3-digit sector of activity fixed effect interacted with the municipality fixed effect. 
Figure 11: Heterogeneous Responses in Employment and Exit by Incumbents

\section{Employment}

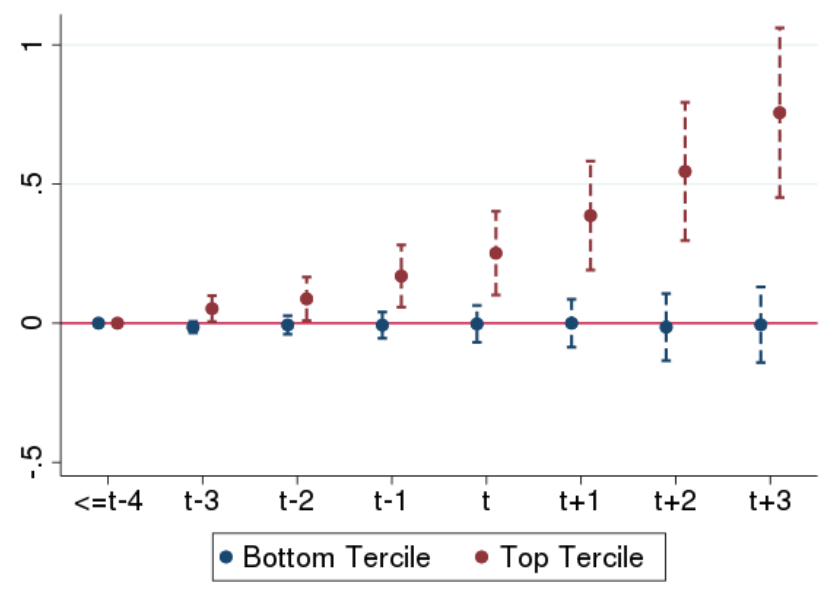

Exit

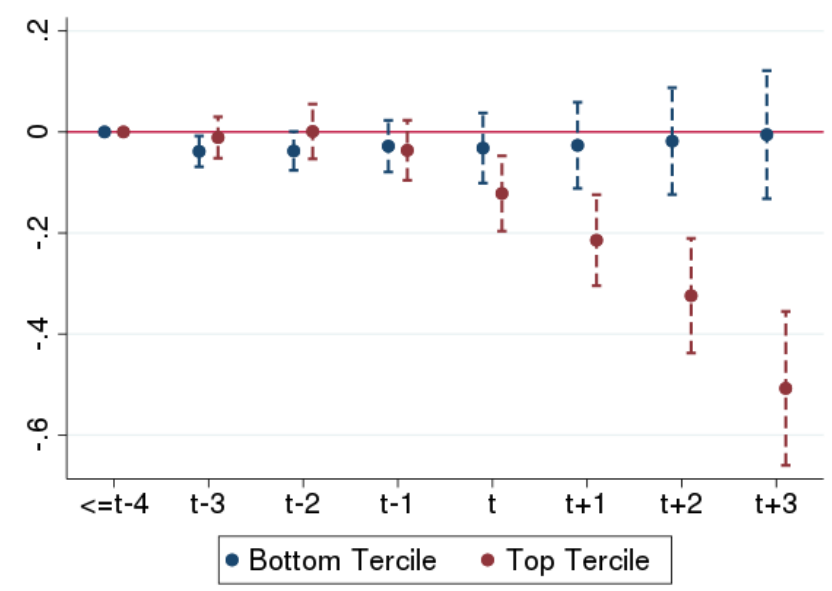

The figures show the estimates of $\beta_{\tau}$ from the regression of municipality-level aggregates for firms in the top and bottom terciles of the productivity distribution measured in 2004. We proxy productivity with the value of sales per employee at the firm level. We rank firms based on sales per employees within 3-digit sector of activity, municipality and age group (age 0-5, $6-15,15+)$. Our regression model is specified as follows:

$$
y_{m, t}=\alpha_{m}+\delta_{t}+\sum_{\tau=-7}^{\tau=3} \beta_{\tau} \mathbb{1}\left(t-\tau_{0, m}=\tau\right)+\sum_{m} \gamma_{m} \mathbb{1}\left(\text { Municipality }_{m}=1\right) t+\epsilon_{m, t},
$$

where $y_{m, t}=$ total employment per 1,000 residents; total exit per 1,000 residents\}. $\tau_{0, m}$ corresponds to the year in which the One-Stop Shop opened in municipality $m$ and $\gamma$ is a vector of coefficients for municipality-specific trends. Standard errors are clustered at the municipality level. $90 \%$. confidence intervals. 
Figure 12: The Impact of Empresa na Hora for Different Sectors of Economic Activity

Entry

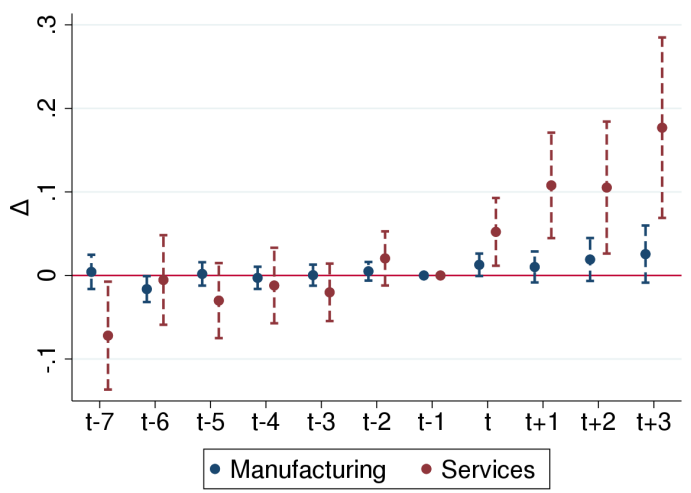

Total Employment

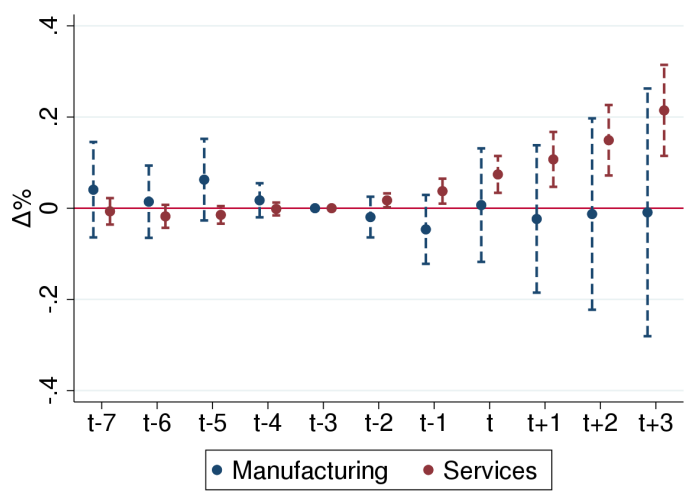

Average Size, Age 0-5

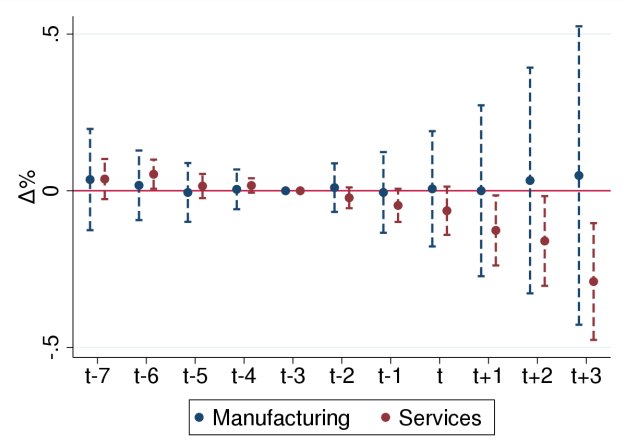

Average Size, Age 6-15

Average Size, Age 15+
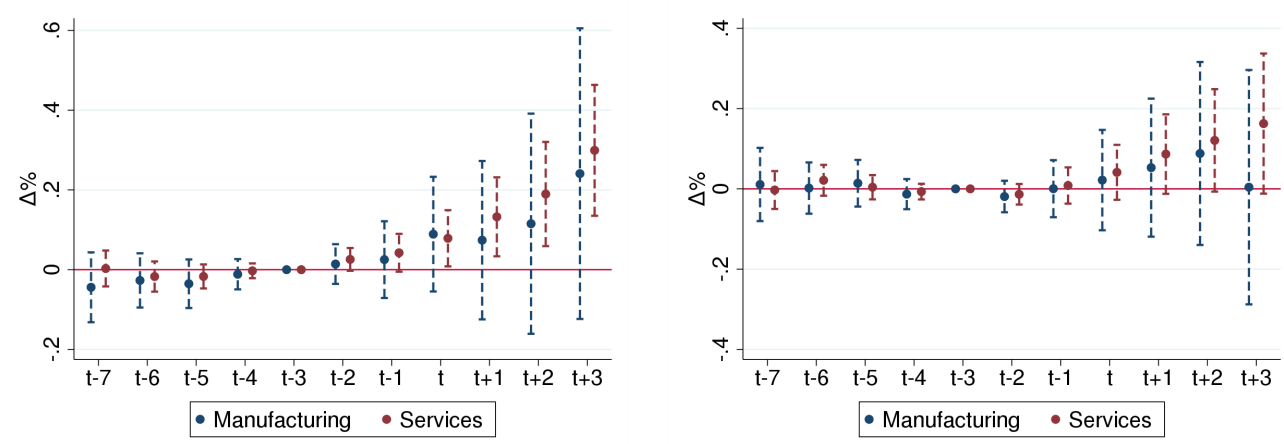

Exit Probability by Age Groups

Manufacturing

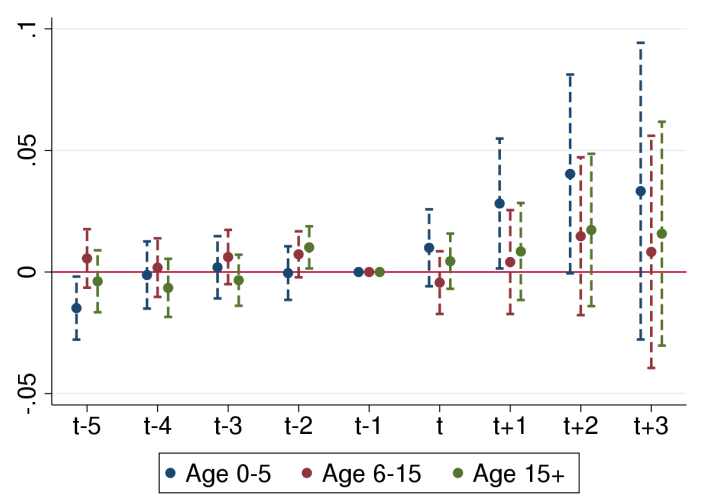

Services

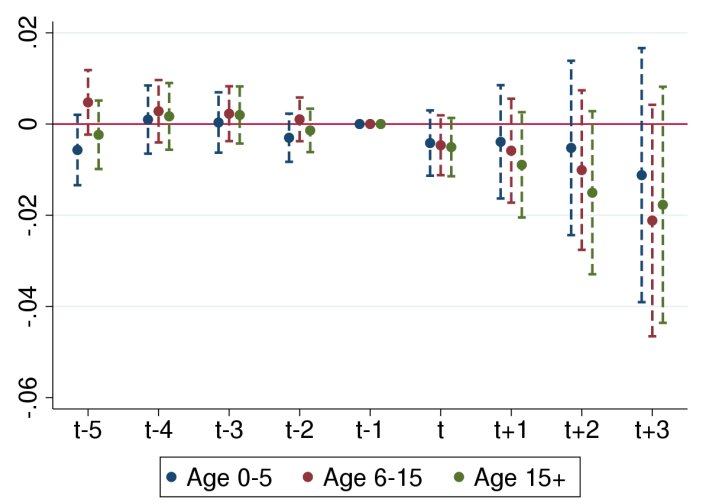

The figures show the estimates of the $\beta_{\tau}$ from the regressions of municipality-level aggregates separately for manufacturing and services. The regressions allow for municipality-specific trends. Standard errors are clustered at the municipality level. $90 \%$ confidence intervals. 


\section{A Appendix}

\section{A.1 Tables and Figures}

Figure 13: Employment and Labor Force Participation in Portugal

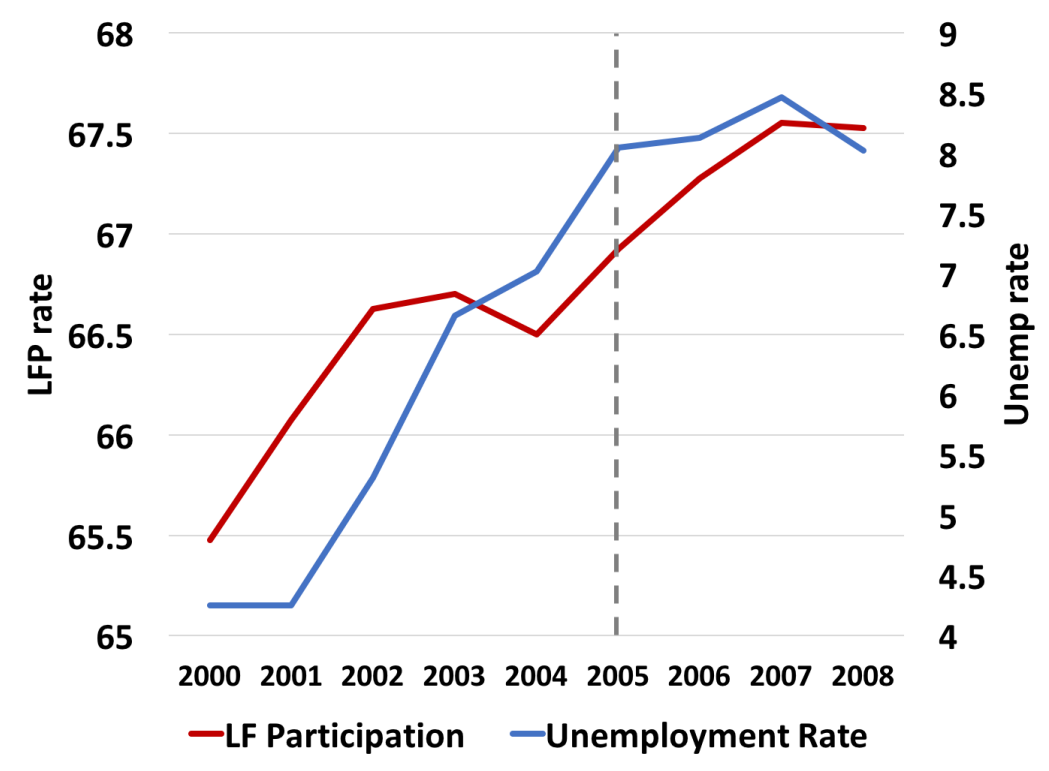


Figure 14: Impact of Empresa Na Hora - Decile-Specific Trends

Entry

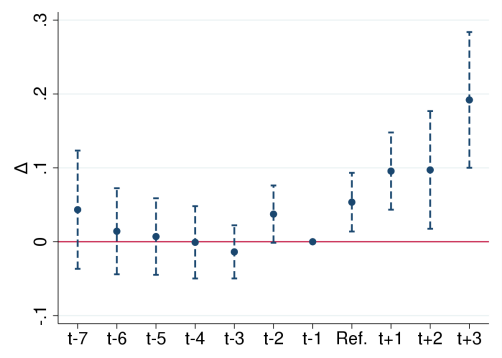

Employment - Age 0-5

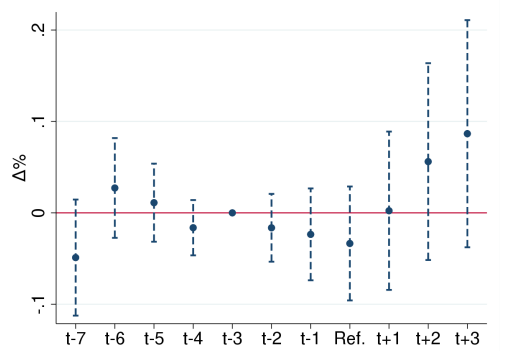

Average Size - Age 0-5

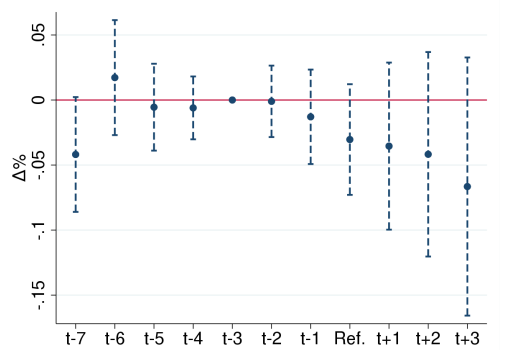

Employment

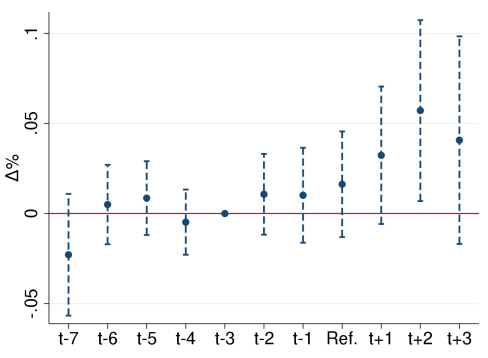

Employment - Age 6-15

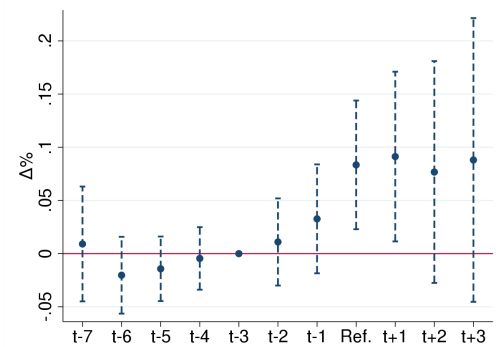

Average Size - Age 6-15

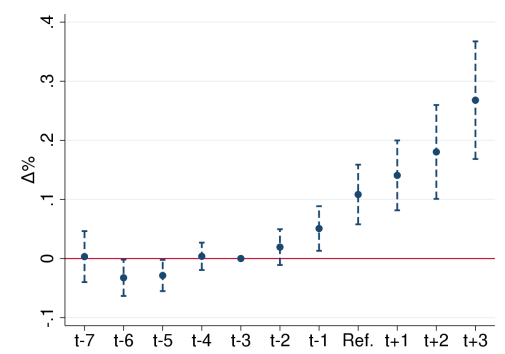

Exit Probability

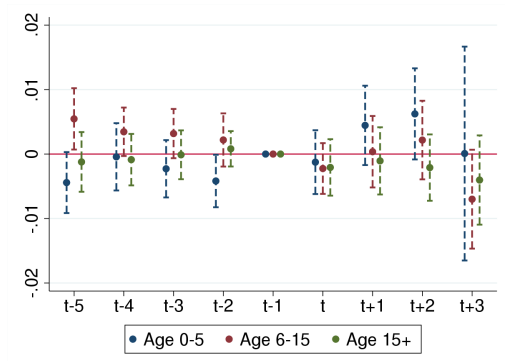

Employment 15+

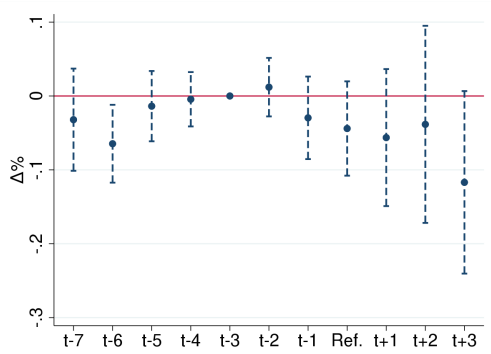

Average Size 15+

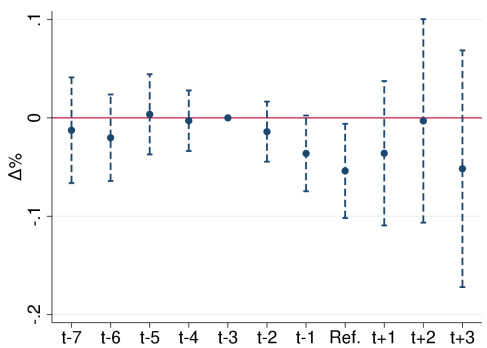

The figures show the estimates of $\beta_{\tau}$ from the following regression at the municipality level:

$$
y_{m, t}=\alpha_{m}+\delta_{t}+\sum_{\tau=-7}^{\tau=3} \beta_{\tau} \mathbb{1}\left(t-\tau_{0, m}=\tau\right)+\sum_{q=1}^{10} \eta_{q} \mathbb{1}\{m \in q\}+\epsilon_{m, t},
$$

$\eta$ is a vector of coefficients for decile-specific trends for municipalities based on the number of residents and the value of sales in services per capita at the municipality level in the pre-period. The regression of the exit probability is run at the firm-level. Standard errors are clustered at the municipality level. 90\% confidence intervals. Entry and Employment measures are normalized per 1,000 residents. 
Figure 15: Heterogeneous Responses in Employment and Exit by Incumbents - Robustness

\section{Employment}

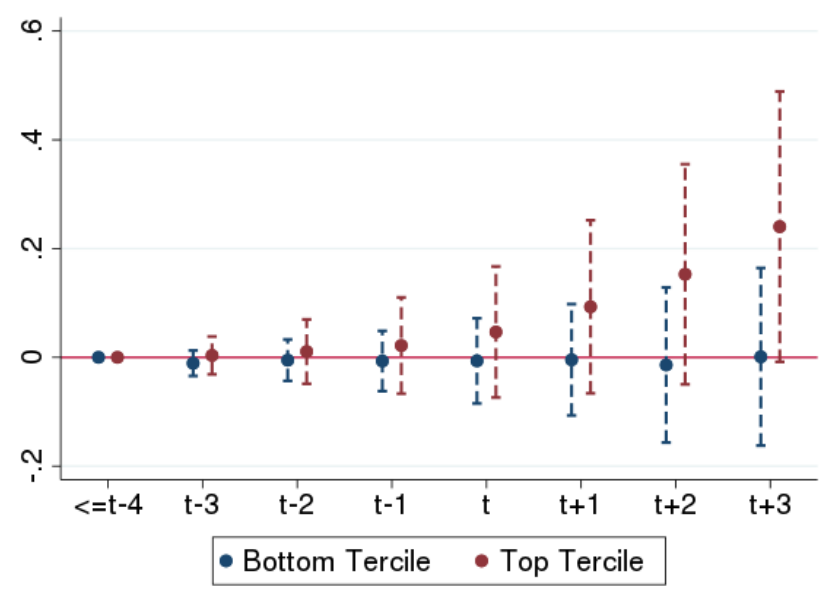

Exit

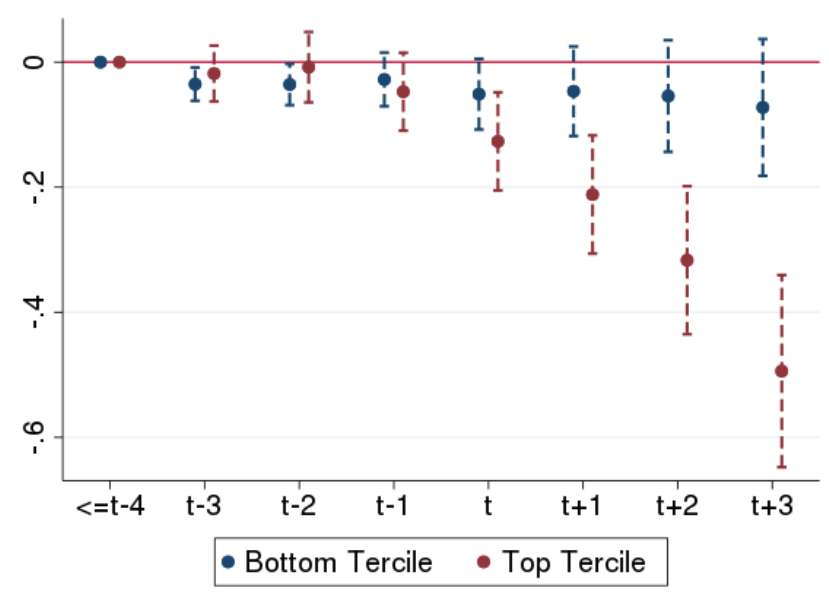

The figures show estimates of $\beta_{\tau}$ from the regression of municipality-level aggregates of the top and bottom terciles of firms productivity as measured in 2004. Differently from the main specification, we rank firms based on sales per employees within 3-digit sector of activity and municipality. That is, we rank across all age groups. Therefore:

$$
y_{m, t}=\alpha_{m}+\delta_{t}+\sum_{\tau=-7}^{\tau=3} \beta_{\tau} \mathbb{1}\left(t-\tau_{0, m}=\tau\right)+\sum_{q=1}^{10} \eta_{q} \mathbb{1}\{m \in q\} t+\epsilon_{m, t},
$$

where $y_{m, t}=$ total employment per 1,000 residents; total exit per 1,000 residents\}. $\tau_{0, m}$ corresponds to the year in which the One-Stop Shop opened in municipality $m . \eta$ is a vector of coefficients for decile-specific trends for municipalities based on the number of residents and the value of sales in services per capita at the municipality level in the pre-period. Standard errors are clustered at the municipality level. 90\% confidence intervals. In Panel (b) we also allow for a 3-digit sector of activity fixed effect interacted with the municipality fixed effect. 
Figure 16: Heterogeneous Responses in Employment and Exit by Incumbents. Decile-Specific Trends
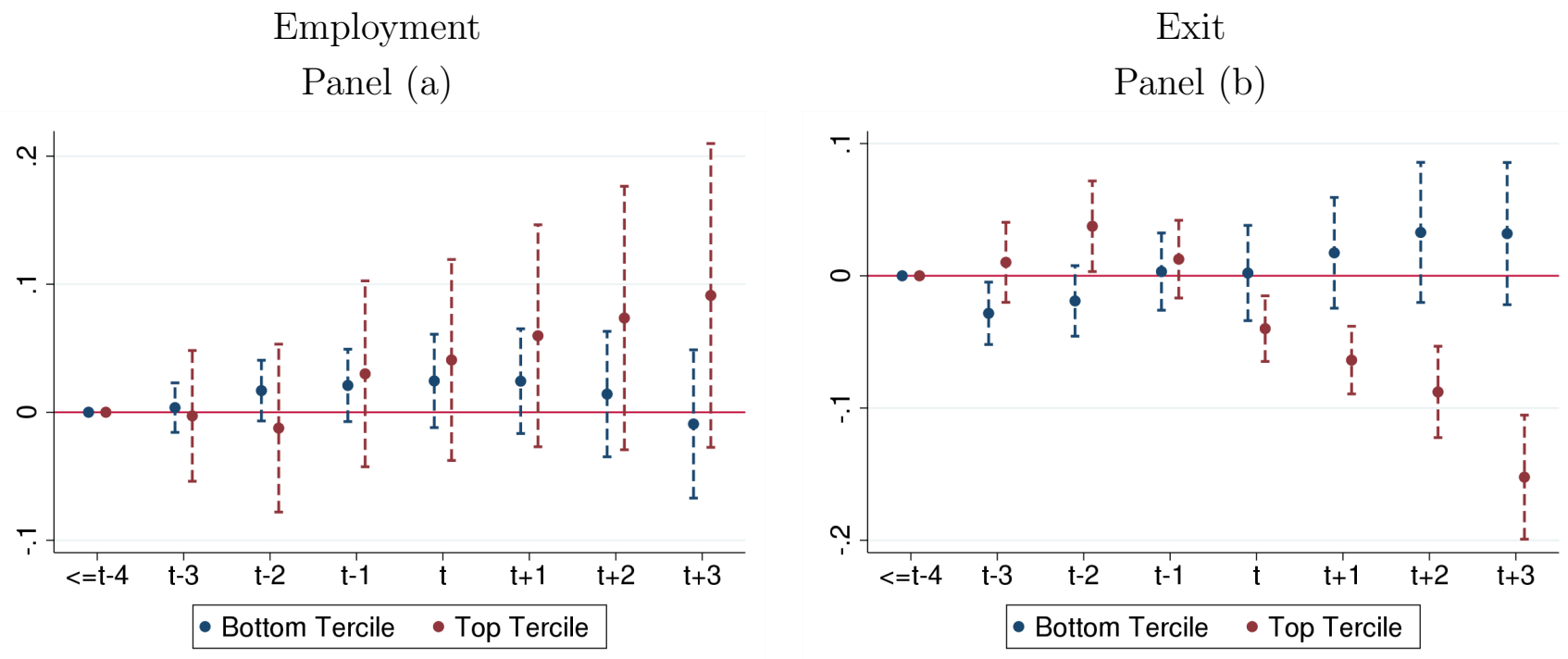

Panel (c)

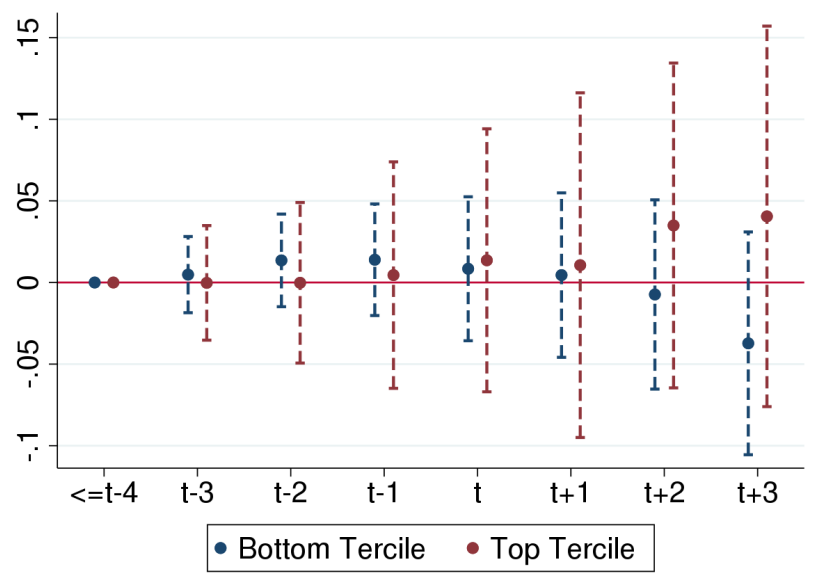

Panel (d)

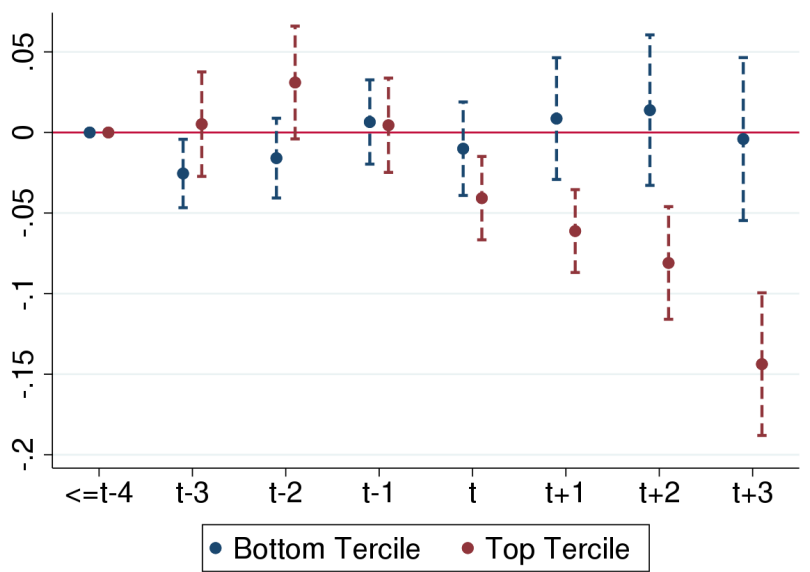

These figures show estimates of $\beta_{\tau}$ from the regression of municipality-level aggregates of firms in the top and bottom terciles of the productivity distribution in 2004. Specifically, we run:

$$
y_{m, t}=\alpha_{m}+\delta_{t}+\sum_{\tau=-7}^{\tau=3} \beta_{\tau} \mathbb{1}\left(t-\tau_{0, m}=\tau\right)+\sum_{q=1}^{10} \eta_{q} \mathbb{1}\{m \in q\}+\epsilon_{m, t},
$$

where $y_{m, t}=$ total employment per 1,000 residents; total exit per 1,000 residents\}. $\tau_{0, m}$ corresponds to the year in which the One-Stop Shop opened in municipality $m . \eta$ is a vector of coefficients for decile-specific trends for municipalities based on the number of residents and the value of sales in services per capita at the municipality level in the pre-period. Panels (a) and (b) use the ranking of firms' productivity within 3-digit sector of activity, municipality and age group. Panels (c) and (d) rank firms within 3-digit sector of activity and municipality. Employment and exit are normalized per 1,000 residents. Standard errors are clustered at the municipality level. $90 \%$ confidence intervals. 


\section{A.2 Derivations and Proofs}

\section{Proof of Proposition 1}

Proof. Given our assumption on production being linear in labor, we have that $l_{i}=\frac{y_{i}}{a_{i}}$. Using the expression for $y_{i}$ under CES in (13), we get

$$
l_{i}=\frac{y_{i}}{a_{i}}=\left(\frac{\sigma}{\sigma-1} \frac{1}{a_{i}}\right)^{-\sigma} \frac{1}{a_{i}} P^{\sigma} Y,
$$

where $Y=\frac{E}{P}$ is the aggregate final good produced, which is both used for consumption and payment of the entry cost, as described in (12). Since under CES $p_{i}=\frac{\sigma}{\sigma-1} \frac{1}{a_{i}}$, we can replace $P$ and get

$$
l_{i}=a_{i}^{\sigma-1} M^{\frac{\sigma}{1-\sigma}}\left[\mathbb{E}\left(a^{\sigma-1}\right)\right]^{\frac{\sigma}{1-\sigma}} Y .
$$

Since we need an expression for $l_{i}$ that only depends on exogenous variables, we now solve for $Y$ in closed form. Using equation 23 for two different firms, we have

$$
\frac{l_{i}}{l_{j}}=\left(\frac{a_{i}}{a_{j}}\right)^{\sigma-1} .
$$

We know that $L=\int_{0}^{M} l_{i} d i$, then

$$
L=\int_{0}^{M}\left(\frac{a_{i}}{a_{j}}\right)^{\sigma-1} l_{j} d i=l_{j} a_{j}^{1-\sigma} \int_{0}^{M} a_{i}^{\sigma-1} d i .
$$

Hence

$$
l_{j}=a_{j}^{\sigma-1}\left[\int_{0}^{M} a_{i}^{\sigma-1} d i\right]^{-1} L .
$$

Using the fact that $y_{i}=a_{i} l_{i}$ and that $Y=\left(\int_{0}^{M} y_{i}^{\frac{\sigma-1}{\sigma}} d i\right)^{\frac{\sigma}{\sigma-1}}$ we get the following:

$$
y_{j}^{\frac{\sigma-1}{\sigma}}=a_{j}^{\sigma-1}\left[\int_{0}^{M} a_{i}^{\sigma-1} d i\right]^{\frac{1-\sigma}{\sigma}} L^{\frac{\sigma-1}{\sigma}} .
$$

Integrating over $j$ and raising both sides to $\frac{\sigma-1}{\sigma}$ we finally get:

$$
Y=\left[\mathbb{E}\left(a^{\sigma-1}\right)\right]^{\frac{1}{\sigma-1}} M^{\frac{1}{\sigma-1}} L .
$$

As a final step we need an expression for $L$. Using the equation for labor supply and the normalization $w=1$ we get:

$$
L=P^{-\nu}=\left(\int_{0}^{M}\left(\frac{\sigma}{\sigma-1}\right)^{1-\sigma} a_{i}^{\sigma-1} d i\right)^{-\frac{\nu}{1-\sigma}}=\left(\frac{\sigma}{\sigma-1}\right)^{-\nu} M^{-\frac{\nu}{1-\sigma}}\left[\mathbb{E}\left(a^{\sigma-1}\right)\right]^{-\frac{\nu}{1-\sigma}}
$$


Plugging both (28) and (29) into (24) we get:

$$
l_{i}=a_{i}^{\sigma-1} M^{-\left(\frac{1-\sigma+\nu}{1-\sigma}\right)}\left(\frac{\sigma}{\sigma-1}\right)^{-\nu}\left[\mathbb{E}\left(a^{\sigma-1}\right)\right]^{-\frac{1-\sigma+\nu}{1-\sigma}} .
$$

Taking $\operatorname{logs}$ and computing $\frac{\partial \ln l_{i}}{\partial \ln M}$ we get that

$$
\frac{\partial \ln l_{i}}{\partial \ln M}=\left(\frac{1-\sigma+\nu}{1-\sigma}\right)>0 \quad \text { if } \quad \sigma<1+\nu .
$$

This proves the first result of the Proposition. The second result follows from computing $\frac{\partial^{2} \ln l_{i}}{\partial \ln M \partial \ln a_{i}}$ from (30). We get,

$$
\frac{\partial^{2} \ln l_{i}}{\partial \ln M \partial \ln a_{i}}=0 \quad \forall i
$$

\section{Proof of Proposition 2}

Proof. This follows immediately from (29), once we take $\operatorname{logs}$ and compute $\frac{\partial \ln L}{\partial \ln M}=\frac{\nu}{\sigma-1}$.

\section{Main Derivations of the Translog Demand Model}

- Derivation of the demand level of each variety: $q_{i}$.

We start from the expression of market share $s_{i}=\frac{1}{M}-\gamma\left(\ln p_{i}-\overline{\ln p}\right)$ presented in equation (19') in Feenstra (2003), which he derives by using the equality $s_{i}=\frac{\partial \ln E}{\partial \ln p_{i}}$. We then use the fact that $q_{i}=s_{i} \frac{E}{p_{i}}$. So that:

$$
q_{i}=\left[\frac{1}{M}-\gamma\left(\ln p_{i}-\overline{\ln p}\right)\right] \frac{E}{p_{i}}
$$

where $\overline{\ln p}=\left(\frac{1}{M} \int 0^{M} \ln p_{i} d i\right)$. 
- Derivation of the aggregate price index.

$$
\begin{aligned}
l \ln P & =\frac{1}{2 \gamma M}+\int_{i=1}^{M} \frac{1}{M} \ln p_{i}+\frac{1}{2} \int_{0}^{M} \int_{0}^{M} \frac{\gamma}{M} \ln p_{i}\left(\ln p_{j}-\ln p_{i}\right) d i d j \\
& =\frac{1}{2 \gamma M}+\int_{a} \ln p(a) d F(a)+\frac{1}{2} \int_{0}^{M} \int_{0}^{M} \frac{\gamma}{M} \ln p_{i}\left(\ln p_{j}-\ln p_{i}\right) d i d j \\
& =\frac{1}{2 \gamma M}+\int_{a} \ln p(a) d F(a)+\frac{1}{2} \gamma \int_{a_{1}} \int_{0}^{M} \ln p\left(a_{1}\right)\left(\ln p_{j}-\ln p\left(a_{1}\right)\right) d j d F\left(a_{1}\right) \\
& =\frac{1}{2 \gamma M}+\mathbb{E}(\ln p(a))+\frac{1}{2} \gamma M \int_{a_{1}} \ln p\left(a_{1}\right)\left(\overline{\ln p}-\ln p\left(a_{1}\right)\right) d F\left(a_{1}\right) \\
& =\frac{1}{2 \gamma M}+\mathbb{E}(\ln p(a))+\frac{1}{2} \gamma M\left[(\overline{\ln p})^{2}-\int_{a_{1}}\left(\ln p\left(a_{1}\right)\right)^{2} d F\left(a_{1}\right)\right] \\
& =\frac{1}{2 \gamma M}+\mathbb{E}(\ln p(a))-\frac{1}{2} \gamma M \mathbb{V}(\ln p(a))
\end{aligned}
$$

- Derivation of the elasticity and markup of each firm: $\epsilon_{i}$ and $\mu_{i}$.

From (31), we can write:

$$
\begin{aligned}
\ln q_{i} & =\ln \left[\frac{1}{M}-\gamma\left(\ln p_{i}-\overline{\ln p}\right)\right]+\ln E-\ln p_{i} \\
-\frac{\partial \ln q_{i}}{\partial \ln p_{i}} & =-\frac{\partial \ln \left[\frac{1}{M}-\gamma\left(\ln p_{i}-\overline{\ln p}\right)\right]}{\partial \ln p_{i}}+1 \\
-\frac{\partial \ln q_{i}}{\partial \ln p_{i}} & =\gamma \frac{1}{s_{i}}+1 .
\end{aligned}
$$

Then, using the expression for markups $\mu_{i}=\frac{\epsilon_{i}}{\epsilon_{i}-1}$, we get:

$$
\mu_{i}=\frac{1+\frac{\gamma}{s_{i}}}{\frac{\gamma}{s_{i}}}=1+\frac{s_{i}}{\gamma}
$$

\section{Proof of Proposition 3}

Proof. We start from the equation for the elasticity $\varepsilon_{i}$ defined in (21). Taking logs we get

$$
\ln \varepsilon_{i}=\ln \left(1+\frac{\gamma}{s_{i}}\right)
$$

so that

$$
\frac{\partial \ln \varepsilon_{i}}{\partial \ln M}=-\gamma \frac{1}{\left(1+\frac{\gamma}{s_{i}}\right) s_{i}^{2}} \frac{\partial s_{i}}{\partial \ln M} .
$$

While the first ratio of (32) is positive, we now need to $\operatorname{sign} \frac{\partial s_{i}}{\partial \ln M}$. We start from the expression for $s_{i}$ in (20), and substitute the expression for $p_{i}$ in (19) and for $\overline{\ln p}$ equal to

$$
\overline{\ln p}=\int_{0}^{M} \frac{1}{M} \ln p_{i} d i=\int_{0}^{M} \frac{1}{M} \ln \left(\left(1+\frac{s_{i}}{\gamma}\right) \frac{1}{a_{i}}\right) d i=\int_{0}^{M} \frac{1}{M} \ln \left(1+\frac{s_{i}}{\gamma}\right) d i-\overline{\ln a} .
$$


We then get the following expression for $s_{i}$ :

$$
s_{i}=\frac{1}{M}+\gamma\left[\int_{0}^{M} \frac{1}{M} \ln \left(\frac{s_{j}}{\gamma}+1\right) d j-\overline{\ln a}\right]-\gamma \ln \left(1+\frac{s_{i}}{\gamma}\right)+\gamma \ln a_{i},
$$

which we rewrite as

$$
s\left(a_{i}\right)=\frac{1}{M}+\gamma\left[\int \ln \left(\frac{s\left(a_{j}\right)}{\gamma}+1\right) d F\left(a_{j}\right)\right]-\gamma \overline{\ln a}-\gamma \ln \left(1+\frac{s\left(a_{i}\right)}{\gamma}\right)+\gamma \ln a_{i} .
$$

Taking derivatives with respect to $\ln M$ we get

$$
\frac{\partial s\left(a_{i}\right)}{\partial \ln M}=\frac{1}{1+\frac{1}{1+\frac{s\left(a_{i}\right)}{\gamma}}}\left(-\frac{1}{M}+\gamma \int \frac{1}{1+\frac{s\left(a_{j}\right)}{\gamma}} \frac{\partial s\left(a_{j}\right)}{\partial \ln M} d F\left(a_{j}\right)\right) .
$$

Further deriving with respect to $\ln a_{i}$ we get:

$$
\frac{\partial^{2} s\left(a_{i}\right)}{\partial \ln M \partial \ln a_{i}}=-\frac{1}{1+\frac{\gamma^{2}}{\gamma+s\left(a_{i}\right)}} \frac{1}{\left(1+\frac{s\left(a_{i}\right)}{\gamma}\right)^{2}} \frac{\partial s\left(a_{i}\right)}{\partial \ln a_{i}} \frac{\partial s\left(a_{i}\right)}{\partial \ln M}
$$

Given that the first three components of the right hand side are all positive, the sign of $\frac{\partial^{2} s\left(a_{i}\right)}{\partial \ln M \partial \ln a_{i}}$ is determined by the sign of $\frac{\partial s\left(a_{i}\right)}{\partial \ln M}$. Suppose that the sign of $\frac{\partial s\left(a_{i}\right)}{\partial \ln M}$ depends on $a_{i}$, i.e., it is not positive for all $a_{i}$, or negative for all $a_{i}$, or zero for all $a_{i}$. By continuity, there exists an $a_{i}$ such that $\frac{\partial s\left(a_{i}\right)}{\partial \ln M}=0$, then $\frac{\partial^{2} s\left(a_{i}\right)}{\partial \ln M \partial \ln a_{i}}=0$. This implies that $\frac{\partial^{2} s\left(a_{i}\right)}{\partial \ln M \partial \ln a_{i}}=0$ for all $i$. Consequently, $\frac{\partial s\left(a_{i}\right)}{\partial \ln M}$ cannot change sign. Hence $\frac{\partial s\left(a_{i}\right)}{\partial \ln M}$ satisfies one of these three cases: (i) it is always zero, (ii) it is always positive, (iii) it is always negative.

To determine which is the case, consider the following:

$$
\int s\left(a_{i}\right) d F\left(a_{i}\right)=\frac{1}{M}
$$

By totally differentiating both sides by $\ln M$ we get that

$$
\int \frac{\partial s\left(a_{i}\right)}{\partial \ln M} d F\left(a_{i}\right)=-\frac{1}{M}
$$

Hence

$$
\frac{\partial s\left(a_{i}\right)}{\partial \ln M}<0 \quad \forall i
$$

Plugging into equation (32) we have that:

$$
\frac{\partial \ln \varepsilon_{i}}{\partial \ln M}>0, \quad \forall i
$$




\section{Proof of Proposition 4}

Proof. We start from $l_{i}=\frac{s_{i} E}{p_{i} a_{i}}$. We take logs and replace the expression for $\ln p_{i}$ from (19). We then get

$$
\ln l_{i}=\underbrace{\ln s_{i}-\ln \left(1+\frac{s_{i}}{\gamma}\right)}_{\equiv \Phi\left(s_{i}\right)}+\ln E
$$

In order to derive $\frac{\partial^{2} \ln l_{i}}{\partial \ln M \partial \ln a_{i}}$, we start from

$$
\frac{\partial \Phi\left(s_{i}\right)}{\partial \ln M}=\frac{\gamma}{s_{i}\left(\gamma+s_{i}\right)} \frac{\partial s_{i}}{\partial \ln M}
$$

Then

$$
\frac{\partial^{2} \ln l_{i}}{\partial \ln M \partial \ln a_{i}}=-\frac{\gamma}{\left(s_{i}\left(\gamma+s_{i}\right)\right)^{2}} \underbrace{\frac{\partial s_{i}}{\partial \ln a_{i}}}_{>0}\left(2 s_{i}+\gamma\right) \underbrace{\frac{\partial s_{i}}{\partial \ln M}}_{<0}+\frac{\gamma}{\left(s_{i}\left(\gamma+s_{i}\right)\right)} \underbrace{\frac{\partial^{2} s_{i}}{\partial \ln M \partial \ln a_{i}}}_{>0}>0 .
$$

\section{Proof of Proposition 5}

Proof. Let us start from the expression for labor supply $L=P^{-\nu}$, where we used the normalization $w=1$. We know that $\frac{\partial P}{\partial p_{i}}>0$ and that $p_{i}=\left(1+\frac{s_{i}}{\gamma}\right) \frac{1}{a_{i}}$.

From (37) we know that $\frac{\partial s_{i}}{\partial \ln M}<0$, hence $\frac{\partial \overline{\ln P}}{\partial \ln M}<0$. Since $\ln L=-\nu \overline{\ln P}$, aggregate labor $L$ increases after the reform. 